\title{
The ageing lung under stress
}

\author{
Martina Korfei $\mathbb{1}^{1,4}$, BreAnne MacKenzie ${ }^{2}$ and Silke Meiners ${ }^{3,4}$
}

Affiliations: ${ }^{1}$ Biomedical Research Center Seltersberg (BFS) and Dept of Internal Medicine, Justus-LiebigUniversity Giessen, Universities of Giessen and Marburg Lung Center (UGMLC), Giessen, Germany. ${ }^{2}$ Lung Therapeutics, Inc., Austin, TX, USA. ${ }^{3}$ Comprehensive Pneumology Center (CPC), University Hospital of the Ludwig-Maximilians-University (LMU) and Helmholtz Zentrum München, Munich, Germany. ${ }^{4}$ Member of the German Centre for Lung Research (DZL).

Correspondence: Martina Korfei, Biomedical Research Center Seltersberg (BFS), Justus-Liebig-University Giessen, Schubertstrasse 81, D-35392 Giessen, Germany. E-mail: Martina.Korfei囚innere.med.uni-giessen.de

@ERSpublications

The ageing lung under stress https://bit.ly/2B3UOru

Cite this article as: Korfei M, MacKenzie B, Meiners S. The ageing lung under stress. Eur Respir Rev 2020; 29: 200126 [https://doi.org/10.1183/16000617.0126-2020].

ABSTRACT Healthy ageing of the lung involves structural changes but also numerous cell-intrinsic and cell-extrinsic alterations. Among them are the age-related decline in central cellular quality control mechanisms such as redox and protein homeostasis. In this review, we would like to provide a conceptual framework of how impaired stress responses in the ageing lung, as exemplified by dysfunctional redox and protein homeostasis, may contribute to onset and progression of COPD and idiopathic pulmonary fibrosis (IPF). We propose that age-related imbalanced redox and protein homeostasis acts, amongst others (e.g. cellular senescence), as a "first hit" that challenges the adaptive stress-response pathways of the cell, increases the level of oxidative stress and renders the lung susceptible to subsequent injury and disease. In both COPD and IPF, additional environmental insults such as smoking, air pollution and/or infections then serve as "second hits" which contribute to persistently elevated oxidative stress that overwhelms the already weakened adaptive defence and repair pathways in the elderly towards non-adaptive, irremediable stress thereby promoting development and progression of respiratory diseases. COPD and IPF are thus distinct horns of the same devil, "lung ageing".

\section{Introduction}

Ageing is the major risk for the decline in lung physiological functions and is therefore associated with increased susceptibility to injury and development of lung diseases. Aged human lungs show characteristic airspace enlargement called "senile emphysema" with similarities to tobacco smoke-related emphysema [1]. Several molecular mechanisms are proposed to contribute to this structural change, including increased oxidative stress [2], DNA damage [3], chronic inflammation [2, 4], replicative senescence caused by telomere shortening [5], mitochondrial dysfunction [3, 6], loss of proteostasis [7], decline of antioxidant defence mechanisms $[8,9]$ and epigenetic alterations resulting in deregulated gene expression [10]. These ageing mechanisms lead to impaired cell-cell communication, deregulated nutrient signalling, defective host defences, decline in immune responses, and altered matrix remodelling [11]. Importantly, this age-related dysregulation contributes to the failure of the lung to respond appropriately to injuries and stressors, causing the eventual demise of cells, defective repair and accumulation of damage over time. Both COPD and idiopathic pulmonary fibrosis (IPF) are diseases of the elderly $[12,13]$, and eminently associated with an accelerated lung ageing process [14]. In addition, altered lung development such as upon early damage of the immature lung has been demonstrated to predispose to the development of COPD, its impact on IPF, however, is less well understood [15]. It is tempting to speculate that the disruption of normal lung development accelerates the process of lung ageing thereby contributing to the increased susceptibility to the

Provenance: Commissioned article, peer reviewed.

Received: 30 April 2020 | Accepted after revision: 22 June 2020

Copyright CERS 2020. This article is open access and distributed under the terms of the Creative Commons Attribution Non-Commercial Licence 4.0. 
development of respiratory diseases [16]. Environmental factors, such as cigarette smoke or other gaseous pollutants, accelerate the ageing of the lung through worsening of ageing-related events and may lead to defective resolution of inflammation, impaired regeneration and insufficient repair. These "second hits" may not only accelerate the progression of both diseases, they also represent an increased risk of the aged, vulnerable lung to develop one of these lung diseases and may act as "final elicitors" for the onset of COPD or IPF $[17,18]$. However, the distinct mechanisms that predispose the old, vulnerable lung to develop either COPD or IPF after the "decisive injury" are still elusive, but distinct cell types might be involved. COPD lungs show increased endothelial cell and fibroblast apoptosis [19-22], as well as destruction of connective tissue including alveolar septae [14, 23], resulting in an irreversible loss of lung tissue and progressive formation of emphysematous spaces (Figure 1). In contrast, the distortion of the alveolar architecture in IPF is characterised by excessive replacement with fibrotic tissue and abnormal bronchiolar epithelium, indicating generation of abnormally excessive tissue (figure 1) [24, 25]. Despite these (cellular) differences, COPD and IPF share a number of the very same ageing mechanisms in the lungs, among them, the presence of senescent cells and a general decline in "adaptive stress responses". Here we propose that such impaired stress response is no longer able to cope with additional challenges to maintain physiological lung function. Instead, the balance is tipped towards "non-adaptive, irremediable stress" which is associated with accumulating damage, cell death, inflammatory signalling and disease progression. COPD and IPF are thus distinct horns of the same devil "lung ageing".

In this review, we would like to provide a conceptual framework of how impaired stress responses in the ageing lung, as exemplified by redox and protein homeostasis, may contribute to onset and progression of COPD and IPF.

\section{Impaired redox homeostasis in the ageing lung}

Cellular redox homeostasis is defined as the maintenance of an oxidant-antioxidant balance in the cell to prevent oxidative stress. The disequilibrium of this balance due to an increased production of oxidants/ reactive oxygen species (ROS) and/or depletion of antioxidants causes oxidative stress in the cell [26]. Antioxidants include enzymatic antioxidants and non-enzymatic, low-molecular weight antioxidant scavengers (e.g. vitamins $\mathrm{C}$ and E) [27]. The process of healthy lung ageing is associated with a progressive decline in antioxidant defence capacity $[8,9,28]$. One underlying reason might be the impaired activity of the antioxidant transcription factor nuclear factor erythroid 2-related factor 2 (NRF2) in aged lung cells [8, 9]. NRF2 signalling drives expression of antioxidant/detoxifying genes, such as heme oxygenase-1 (HMOX1), $\mathrm{NAD}(\mathrm{P}) \mathrm{H}$ quinone oxidoreductase 1 (NQO1) and both subunits of glutamate cysteine ligase (GCLC and GCLM) via the antioxidant response element in their promoter regions [29]. Decreased nuclear NRF2 levels were accompanied with a significant decline in the induction of NRF2-regulated antioxidant genes in primary human bronchial epithelial (HBE) cells from aged donors compared to young controls [9]. Loss of inducibility correlated with an increased expression of the NRF2 inhibitors Bach1 (transcription regulator protein BACH1) and c-Myc [9]. Lung fibroblasts isolated from aged mice also exhibit deficient Nrf2 induction in response to exogenous $\mathrm{H}_{2} \mathrm{O}_{2}$, as compared to young murine fibroblasts [30]. Similarly, mRNA expression of NRF2-targets HMOX1, NQO1 and GCLC was downregulated in $\mathrm{H}_{2} \mathrm{O}_{2}$-treated senescent human IMR90 lung fibroblasts resulting in a reduced ability to detoxify ROS contributing to increased oxidative stress [30]. Impaired induction of NRF2 and NRF2-regulated genes in older cells may thus underlie the increased
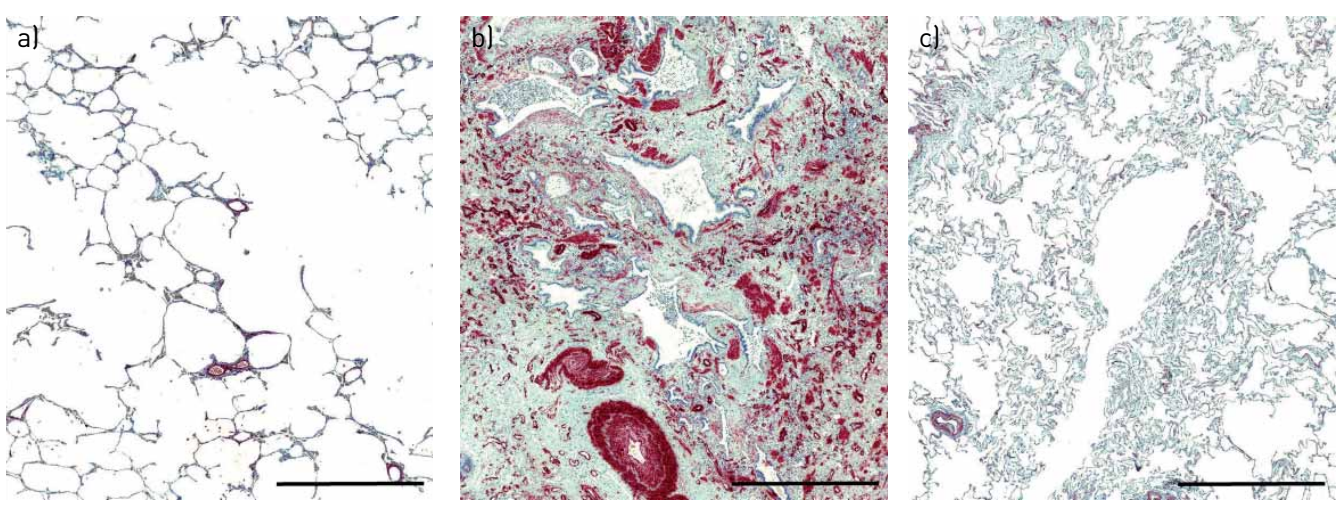

FIGURE 1 Lung histology of a) a 62-year-old patient with COPD, b) a 64-year-old patient with idiopathic pulmonary fibrosis and c) a 61-year-old organ donor. All patients are male and are (former) smokers. Shown is a representative immunohistochemistry for alpha-smooth-muscle-actin ( $\alpha$-SMA). Scale bar=1 mm. 
susceptibility of the elderly to oxidative stress and lung disease triggered by ROS [9]. Oxidative stress results in detrimental oxidative modifications and molecular damage to cellular proteins, lipids and RNA/DNA, impairing their function and contributing to shortened life span [26]. Oxidative damage to DNA results in either cell cycle arrest through the p53/p21 ${ }^{\mathrm{CIP} 1}$ pathway or cell death via p53-induced apoptotic pathways if the dose and damage is too great $[31,32]$. Lipid peroxidation exerts its detrimental effects through two main mechanisms [33]. Extensive peroxidation of lipids alters the assembly, composition, structure and dynamics of lipid membranes including the plasma membrane. Furthermore, lipid peroxides degrade very fast into highly reactive aldehydes, with 4-hydroxynonenal (4-HNE) and malondialdehyde being the best described [34], which react with proteins to create irreversible oxidative protein modifications through formation of covalent carbonyl adducts [33]. The oxidative modifications of proteins, e.g. protein carbonylation, which is generated beside lipid peroxide mediated-protein oxidation also through direct oxidation of amino acid side-chains by oxygene radicals, affects the physical and chemical properties of proteins, including conformation, structure, solubility, susceptibility to proteolysis and enzyme activities [35, 36]. This can be detrimental for cellular function and promotes accelerated ageing processes as demonstrated for example for the anti-ageing molecule sirtuin-1, an enzyme involved in mitochondrial biogenesis and antioxidant induction, whose deacetylase activity declines with the ageing process in the liver, kidney, heart and lung due to protein oxidation [37, 38]. Moreover, excessive ROS and oxidation of sirtuin-1 promote its proteasomal degradation [38, 39].

Concomitant with an impaired antioxidative capacity, elevated levels of oxidative stress associated damage have been observed in aged tissue, including the lungs [8, 28, 40, 41]. Among them, BRAIDY et al. quantified the levels of oxidative stress in the form of protein carbonyls, lipid peroxidation, and oxidative DNA damage in the liver, heart, kidney and lung from female wistar rats aged 3 to 24 months, thus spanning life stages from young adulthood to old age. Middle-age (12-month-old) rats already exhibited higher levels of oxidatively modified proteins, lipids and DNA than young adult animals aged 3 months. This was further accelerated massively after 12 months of age in all organs [28]. Moreover, accumulating oxidative insults to macromolecules may promote cell death via apoptotic and non-apoptotic mechanisms $[42,43]$. In accordance, aged organs generally demonstrate significantly lower cell volumes, indicative of cell loss due to increased cell death occurring during the ageing process [28].

Taken together, the aged lung is primed to oxidative stress. This is at least in part caused by an age-related decline in the antioxidative capacity of aged cells due to reduced activity of the antioxidant master regulator NRF2.

\section{Redox imbalance and oxidative stress in COPD \\ Decline in antioxidant capacity}

In aged smokers and COPD patients, redox homeostasis as maintained by NRF2-BACH1 equilibrium is dysregulated in the lung including alveolar macrophages [44]. Consistent with these findings, Nrf2-deficient mice are more susceptible to cigarette smoke exposure (CSE) and develop more severe lung emphysema and apoptosis, and the activity of antioxidant enzymes is repressed [45]. Moreover, other protective antioxidant mechanisms are not sufficiently adapted in elderly smokers and COPD patients as the increase of superoxide dismutase (SOD) expression is lacking, so that oxidants may subsequently take over the leading role [46, 47]. Kondo et al. [47] observed that superoxide $\left(\mathrm{O}_{2}{ }^{--}\right)$anion generation (briefly superoxide) in alveolar macrophages of elderly smokers was presumably due to proteolytic degradation of SOD in elderly smokers, while mRNA level were not altered compared to age-matched nonsmokers. The failure of cells to induce antioxidants such as SODs can also be explained by inactivation and loss of the anti-ageing molecule sirtuin-1 in COPD lungs which is known to protect against oxidative stress by upregulating forkhead box O3A (FOXO3A) transcriptional activity and FOXO3A-dependent antioxidant genes, such as catalase and $\mathrm{MnSOD}$ (manganese SOD) [38, 39, 46]. FOXO3A expression itself is significantly decreased in the lungs of smokers and patients with COPD [48]. Furthermore, although the expression of various glutathione peroxidases (GPXs) is increased in smokers and COPD patients, GPX activity is significantly reduced in both groups in comparison to nonsmokers [49]. Impaired GPX function can be due to general increase in protein oxidation which has been observed in various cell types of COPD lungs [50].

Chronic oxidative stress

In COPD, the foremost risk factor leading to the development of disease besides ageing is tobacco smoke consumption $[17,51]$. Cigarette smoke contains numerous highly reactive chemical compounds causing oxidative stress [52]. For the ageing lungs, cigarette smoke exposure represents a major additional challenge of the already reduced redox balance resulting in chronic oxidative stress. There is documented evidence that superoxide-generating (phagocytic and non-phagocytic) NADPH oxidases (NOX) are involved in mediating the cytotoxic effects of cigarette smoke [53-57]. Thiol-reactive compounds in cigarette smoke-induced endothelial superoxide production via NOX2 in cell- and tissue-culture systems, 
which was associated with increased peroxynitrite $\left(\mathrm{ONOO}^{-}\right)$formation (nitrosative stress), enhanced expression of pro-inflammatory cytokines and endothelial dysfunction [53, 54]. Inhibitors of NOX enzymes reduced cigarette smoke-induced superoxide production and its deleterious consequences in endothelial cells $[53,54]$. Importantly, the lung shows high basal expression of NOX enzymes, and nearly all NOX family members are upregulated in response to cigarette smoke exposure in vitro and/or in COPD lungs in vivo (reviewed in [57]), indicating that ROS derived from NOX enzymes play a crucial role in COPD pathogenesis. In agreement, it was shown that bronchoalveolar lavage (BAL) leukocytes isolated from COPD patients release high levels of superoxide which was linked to increased levels of inflammatory mediators and oxidative stress in the air spaces [55, 56, 58]. Levels of $\mathrm{H}_{2} \mathrm{O}_{2}$, the dismutation product of superoxide, are much higher in the exhaled breath condensate of COPD patients than of healthy controls, and correlate with disease severity [59]. Oxidative stress and damage in COPD are further represented by increased lipid peroxidation and protein oxidation in both the airway and alveolar epithelia of patients [50], as well as by oxidant-induced DNA damage in bronchial epithelial cells, type-II alveolar epithelial cells (AECII), septal endothelial cells, macrophages and fibroblasts of COPD lungs [21, 22, 60]. DNA oxidation has a crucial role in COPD pathogenesis [61] because it promotes further ROS generation [60, 61], mediates microsatellite instability [62], inhibits DNA methylation [63], impairs DNA repair [60,64] and accelerates telomere shortening [65], resulting in somatic mutations in patients with COPD [60, 64]. Increased nucleic acid oxidation in RNA and DNA has been reported in alveolar wall cells, in particular in alveolar fibroblasts, in both the mouse model of cigarette smoke-induced emphysema and in COPD lung tissue, and correlated with the severity of disease $[21,22]$. In vitro studies also underscored that cigarette smoke induces nucleic acid oxidation in lung fibroblasts, inhibits the recruitment and proliferation of lung fibroblasts, and activates apoptosis [22, 66, 67]. Oxidant-mediated injury in alveolar fibroblasts targets destruction of alveolar collagen and elastic fibres required to maintain the architecture of the alveolus, thereby leading to emphysema formation [68]. It has also been suggested that the increase in alveolar wall/septal cell death in COPD likely involves "anoikis", i.e. cell death by detachment from the underlying extracellular matrix (ECM) [43]. Other pathogenic mechanisms of cigarette smoke and persistent oxidative stress in the "aged stressed COPD lung" include exaggerated airway and lung inflammation and protease/antiprotease imbalance [51, 69]. The inflammatory response to cigarette smoke and oxidative stress is the major aetiological factor in the pathogenesis of COPD [51, 70]. ROS enhances the inflammation through neutrophil accumulation and the activation of mitogen-activated protein kinases and redox-sensitive transcription factors, such as nuclear factor (NF)- $\mathrm{KB}$ and activator protein-1, resulting in increased expression of inflammatory mediators and cytokines (interleukin (IL)-1, tumour necrosis factor (TNF)- $\alpha$, IL-8, granulocyte-macrophage colony-stimulating factor and inducible nitric oxide synthase (iNOS)), that contribute to chronic inflammation in COPD [70, 71]. Neutrophils are the most abundant inflammatory cells present in the bronchial wall and lumen of patients with COPD [72], and are themselves powerful producers of ROS [73], which is believed to be generated by NOX2 [57]. Neutrophil elastase plays an important role in neutrophil-mediated bacterial and fungal killing, but also degrades almost every ECM component, including collagen, fibronectin, proteoglycans, heparin and cross-linked fibrin thereby contributing to emphysema formation in COPD [74]. Despite smoking cessation, oxidative stress, somatic mutations, neutrophil inflammation and apoptosis, as well as activation of adaptive immune responses, persist in the majority of COPD patients [75-80], which can be attributed to the impaired defence of the stressed aged lung.

Interestingly, despite the established role of NOX2 in exaggerating ROS production and inflammation in response to cigarette smoke exposure, genetic ablation of components of Nox2 (p47 $7^{\text {phox(-l-) }}$ and gp91 phox(-/-) ) in mice, in which the phagocytic cells are incapable of respiratory burst and ROS release, did not protect the lungs against detrimental effects of cigarette smoke [81]. Instead, alveolar destruction, inflammatory cell infiltration, inflammatory gene expression, and mucus secretion were significantly augmented in lungs of both $\mathrm{p} 47^{\text {phox(-l-) }}$ and gp91 $1^{\text {phox(-l-) }}$ mice in response to sub-chronic cigarette smoke exposures, as compared to cigarette smoke exposed wild-type mice [81].

Furthermore, dysregulation of iNOS and nitrotyrosine formation have been proposed as contributing pathomechanisms of COPD $[82,83]$. Beside inflammatory IL-6 and IL-8 production, iNOS contribute to increased nitric oxide production and nitrosative stress in COPD, as nitric oxide may react with superoxide $\left(\mathrm{O}_{2}{ }^{--}\right)$to form the potent oxidant peroxynitrite $\left(\mathrm{ONOO}^{-}\right)$[84], which in turn reacts very fast with tyrosine residues from many proteins to form nitrotyrosine $[82,83]$. Increased iNOS expression and nitrotyrosine levels have been observed in the pulmonary vasculature and AECII of both COPD patients and emphysemateous mice upon cigarette smoke exposure, and correlated with induction of apoptosis in these cells [82]. Interestingly, in the study by SEIMETz et al. [82], pulmonary vascular remodelling and pulmonary hypertension $(\mathrm{PH})$ preceded the development of alveolar destruction/emphysema in chronically cigarette smoke-exposed mice. Mice lacking iNOS (Nos2) were protected against cigarette smoke-induced emphysema and $\mathrm{PH}$, and iNOS inhibition both prevented smoke-induced lung damage and reversed $\mathrm{PH}$ and fully established emphysema in wt-mice [82]. Cigarette smoke-induced iNOS 
upregulation and subsequent peroxynitrite formation was also linked to disruption of the soluble guanylate cyclase (sGC) activity in alveolar and endothelial cells in cigarette smoke-exposed rodents and COPD lungs [85]. Stimulators of sGC prevented cigarette smoke-induced $\mathrm{PH}$ and emphysema in rodents through inhibition of alveolar and endothelial cell apoptosis, and reduction of inflammatory gene expression and neutrophil numbers in rodents with long-term exposure to cigarette smoke [85].

Taken together, the persistence of oxidative (and nitrosative) stress and inflammation is driven both by the inactivation or depletion of antioxidant defence capacity of the ageing lung as well as the permanent chronic challenge to oxidants and presents a paradigm for a non-adaptive, irremediable stress responses in COPD.

\section{Redox imbalance and oxidative stress in IPF}

Decline in antioxidant capacity

Strong evidence suggests that impaired redox balance is also involved in the pathogenesis of IPF. Low expression levels of enzymatic antioxidants, including extracellular superoxide dismutase (EcSOD), $M n S O D$, catalase and HMOX1 have been observed in the fibrotic areas [86-88], which may result in increased ROS generation and consecutive damage to the overlying epithelium. Glutathione, a major component of the lung antioxidant defence system, is decreased in the epithelial lining fluid, both in the bleomycin model of lung fibrosis and in IPF patients [89]. These effects might be driven by dysregulation of NRF2, the "master regulator" of the antioxidant response. First, Nrf2 ${ }^{(-)}$knockout mice are more sensitive to bleomycin- and paraquat-induced pulmonary fibrosis compared to wild-type animals [90]. Secondly, NRF2 expression is largely absent in myofibroblasts within fibroblast foci of IPF lungs [30], and coincides with increased NADPH oxidase (NOX)-4 expression and enhanced $\mathrm{H}_{2} \mathrm{O}_{2}$ production [30, 91, 92]. In agreement, in an in vitro study using cultured primary IPF fibroblasts, decreased NRF2 expression was associated with an $\alpha$-smooth muscle actin expressing myofibroblast phenotype, whereas NRF2 activation increased antioxidant defences and abrogated the contractile myofibroblastic phenotype in these IPF fibroblasts [93]. Of particular interest, increased expression of NRF2 has been observed by two independent groups in the AECIIs of IPF lungs [30,94], the chronic injury of which is regarded as the crucial pathogenetic event in IPF. However, expression of two NRF2 target genes, among them peroxiredoxin 1 (PRDX1) [95], was reduced in AECII of IPF lungs compared to cells from patients with nonspecific interstitial pneumonia, an entity with a better outcome than IPF [96]. NRF2 induction may thus represent an attempt of IPF AECIIs to survive under conditions of severe oxidative stress, but is less able to adaptively increase antioxidant enzymes and thus incapable of restoring the redox balance. In contrast, oxidative stress and ROS generation in IPF fibroblasts appear to have a (survival-related) "physiological" function in myofibroblast differentiation and also confers resistance to apoptosis in these cells, which is in marked contrast to interstitial COPD fibroblasts.

\section{Chronic oxidative stress}

Alveolar oxidative stress plays a crucial role in the pathogenesis of IPF and contributes to the fibrotic process by: 1) inducing alveolar epithelial cell injury and apoptosis [97, 98]; 2) increasing the release and activation of profibrotic/inflammatory cytokines and growth factors such as transforming growth factor (TGF)- $\beta[99,100]$, or 3) causing impairment of the pulmonary surfactant system [101].

Biomarkers of oxidative stress, such as protein carbonyls or 8-isoprostane, a lipid peroxidation product, are elevated in BAL fluid of patients with IPF [102-104], and positively correlate with poor clinical outcome [105]. Furthermore, superoxide radicals and $\mathrm{H}_{2} \mathrm{O}_{2}$ are released spontaneously by alveolar macrophages and other BAL cells of IPF patients, which consecutively may result in injury of the alveolar epithelium [86]. In line with this, release and oxidative damage of mitochondrial DNA has been observed in lung epithelial cells of IPF patients [106-108]. This may drive ATP depletion and mitochondrial dysfunction, amplifying ROS generation as the electron transport chain is uncoupled from proton pumping and ROS are released into the cytosol [108]. The profibrotic cytokine TGF- $\beta$ can augment the production of ROS. First, TGF- $\beta$ induces prolonged mitochondrial ROS generation by decreasing complex IV activity in lung epithelial cells, with senescent arrest and persistent disruption of mitochondrial membrane potential [109]. Secondly, TGF- $\beta$ mediated myofibroblast differentiation is associated with the enzymatic production of extracellular $\mathrm{H}_{2} \mathrm{O}_{2}$ that promotes damage to the overlying alveolar epithelium, a key event in initiating and perpetuating fibrosis in IPF [98]. Thirdly, TGF- $\beta$ leads to activation of NOX4 expression in various lung cells in vitro and in vivo to produce ROS [91, 92, 110]. In agreement, NOX4 is strongly overexpressed in the fibroblast foci as well as the hyperplastic AECII of IPF patients [91, 92, 111], and Nox4 deficient mice are protected against bleomycin-induced AECII apoptosis and pulmonary fibrosis [111]. Moreover, pharmacologic inhibition of non-phagocytic Nox4 reversed pulmonary fibrosis in aged mice [30], demonstrating that targeting Nox4 is sufficient to correct oxidative stress and to promote resolution of age-associated fibrosis. These data also highlight the crucial pathogenic role of oxidative stress and ageing 
in the development of lung fibrosis [30]. The increased levels of protein oxidation in IPF lungs, as well as lungs of ageing mice, including protein carbonylation [104] and protein S-glutathionylation (PSSG) [112], which is generated through covalent attachment of glutathione to reactive protein cysteine residues, could be a potential consequence of NOX4- or mitochondrially derived oxidants as well as of the observed decline in antioxidants as described above. Interestingly, the antioxidant glutaredoxin-1 is itself $S$-glutathionylated and inactivated in IPF lungs, thereby amplifying the generation of PSSG protein adducts (and perpetuating depletion of glutathione) [112]. Consistent with alveolar oxidative stress, PSSG patterns were found in AECII of IPF patients, but not in normal AECII of control lungs [112]. Another prominent target for PSSG important in pulmonary fibrosis is the death receptor FAS through its role in augmenting epithelial apoptosis. Fas glutathionylation occurs in response to endoplasmic reticulum redox imbalances in lung epithelial cells and subsequently increases caspase- 3 and -8 activity [113], and was also shown to be upregulated in experimental lung fibrosis and IPF [112].

Finally, oxidative stress is the most commonly cited underlying mechanism for accelerated telomere shortening [114]. Several studies report more single strand breaks and 8-oxoguanine lesions in telomeres as compared to microsatellite repeats and bulk genomic DNA, after exposures to oxidising agents $[115,116]$.

In IPF, telomere attrition appears to predominantly affect AECII $[117,118]$, while no shortening in telomere length is observed in fibroblasts surrounding the injured AECII [117]. Notably, 25\% of sporadic cases of IPF (without any identified genetic cause) reveal shortened telomeres comparable to those in familial IPF with identified telomerase gene mutations $[118,119]$. Cigarette smoke has been considered to be one of the risk factors for sporadic and familial IPF [18] and is shown to cause telomere shortening in a dose-dependent manner [65]. TSAKIRI et al. [120] reported that smokers with a mutation in TERT or TERC die 10 years earlier than nonsmoking IPF patients. In conclusion, in IPF, both, the reduced antioxidant defence and the chronic oxidative stress, contribute to the myoactivation of lung fibroblasts and their resistance to apoptosis and at the same time drive telomere shortening in AECII cells (through oxidative damage to telomeric DNA) which contributes to disease development.

\section{Decline in proteostasis in the ageing lung}

Proteostasis is the synthesis, folding, processing, trafficking and degradation of proteins [121]. Loss of proteostasis contributes to the accumulation of unfolded, misfolded or aggregated proteins and is a hallmark of ageing [122]. The drivers of age-related loss of proteostasis are mainly oxidative stress, endoplasmic reticulum stress, and epigenetic alterations resulting in changed expression profiles of key factors maintaining protein homeostasis [26, 122, 123]. As the result, the activities of the chaperone network and of the two major proteolytic systems, the autophagy-lysosomal system and the ubiquitin-proteasomal system, become significantly deregulated with age in many tissues, especially in liver and lung $[124,125]$.

\section{Impaired chaperone network}

Ageing significantly decreases the levels of molecular chaperones that are required for folding of proteins such as heat shock protein (Hsp)-27, Hsp60 and Hsp70 (includes Hsp72 and Hsc70) in various organs, both at mRNA and protein levels [126-128]. In ageing cells the activity of the master transcription factor heat shock factor (HSF)-1 is reduced as evidenced by diminished binding of HSF1 to heat shock elements (HSE) in HSP promoters in gel shift assays, resulting in an impaired capacity to transcriptionally activate expression of HSPs [126, 129]. Moreover, HSF1 expression itself is significantly reduced in senescent IMR90 lung fibroblasts and skin fibroblasts from older human subjects [129]. In addition to cytosolic HSPs, a decline in protein levels of the endoplasmic reticulum chaperones ERp55 (protein disulfide isomerase (PDI) A1), ERp57 (PDIA3), ERp72 (PDIA4), GRP78, GRP94 and calnexin has been observed in many organs during ageing [130-132]. Interestingly, BOROK et al. [133] observed that AECII isolated from lungs of aged mice showed decreased expression of Grp78, while the endoplasmic reticulum chaperone Grp94 was increased, compared to AECII from 2-month-old mice. As (endoplasmic reticulum) chaperones are progressively oxidised during ageing [134, 135], this may contribute to their functional decline and consequently to impairment in protein folding, disulfide crosslinking and glycosylation. However, there is also evidence of increased expression of HSP and endoplasmic reticulum chaperones (especially GRP78) in some ageing cells [136, 137], and especially under accumulating ROS conditions [138], possibly representing an adaptive response to elevated endogenous oxidative stress in ageing. By using transcriptome profiling, MisRa et al. [138] showed progressive increase in oxidative stress in lungs of healthy ageing DBA/2J mice from 2 months to 20 months of age, which was accompanied by upregulation of stress-response genes including HSP and enzymes involved in xenobiotic detoxification mechanisms. On the contrary, aged $\mathrm{C} 57 \mathrm{Bl} / 6 \mathrm{~J}$ mouse lungs showed downregulation of HSP genes, thus indicating a mouse strain-specific regulation of stress-response genes during lung ageing [138]. 
Endoplasmic reticulum-stress

Endoplasmic reticulum-stress results from misfolding of secretory proteins and leads to the upregulation of a signalling pathway called the endoplasmic reticulum stress response or unfolded protein response (UPR) [139]. The UPR starts when GRP78 dissociates from the three endoplasmic reticulum transmembrane sensors PRKR-like endoplasmic reticulum kinase (PERK), activating transcription factor-6-alpha (ATF6 $\alpha$ ) and inositol requiring enzyme-1-alpha (IRE1 $\alpha$ ), and gets recruited to the misfolded protein cargo, thereby permitting the activation of these "endoplasmic reticulum-stress sensors" and UPR signalling pathways PERK/ eIF2 $\alpha /$ ATF4, ATF6 $\alpha$ and IRE1 $\alpha /$ X-box binding protein-1 (XBP1). The adaptive UPR signalling is characterised by the induction of chaperones, such as GRP78, degradation of misfolded proteins via the endoplasmic reticulum-associated degradation (ERAD) pathway, and attenuation of protein translation [139].

Endoplasmic reticulum stress and oxidative stress are tightly interconnected through increased protein oxidation which disrupts protein folding in the endoplasmic reticulum, leading to accumulation of misfolded oxidised protein substrates. This process is further aggravated by ROS through impaired function of oxidatively modified proteins from chaperoning systems or other cellular "quality control" mechanisms [140, 141]. Moreover, NRF2 is closely associated with ROS-dependent UPR activation as PERK kinase directly phosphorylates NRF2 upon endoplasmic reticulum stress, thereby preventing its proteasomal degradation allowing NRF2 translocation and accumulation in the nucleus [142]. When protective UPR action fails to restore folding capacity in the endoplasmic reticulum, the apoptotic arm of the UPR is activated [139, 143147]. Apoptosis in response to endoplasmic reticulum stress is mediated largely by induction of C/EBP homologous protein (CHOP) [139], which upregulates the transcription of various pro-apoptotic factors [143-146], while it downregulates anti-apoptotic genes such as B-cell leukaemia/lymphoma 2 protein (BCL2) [147]. In addition, CHOP has been implicated in exaggerated ROS production by increasing expression of endoplasmic reticulum oxidoreductase alpha, which contributes to $\mathrm{H}_{2} \mathrm{O}_{2}$ generation during oxidative disulfide bond formation [148]. Furthermore, CHOP leads to intracellular glutathione depletion through upregulation of glutathione-specific gamma-glutamylcyclotransferase-1, which degrades glutathione [149]. Moreover, CHOP is also involved in induction of inflammatory cytokines IL1B [150] and IL6 [151], thereby perpetuating cell injury and death. Endoplasmic reticulum stress-induced inflammation can also be triggered through various pathways induced by hyperactivated p-IRE1 $\alpha$, which may result in NF- $\mathrm{B}$, JNK (c-Jun N-terminal kinase) but also NLRP3 inflammasome activation [139, 152].

Elevated endoplasmic reticulum stress response and UPR activation has been observed in adipose tissue of old compared to young mice, and contributes to adipose tissue inflammation in ageing [136]. In addition, in ageing cells the adaptive UPR mechanisms are weakened, whereas the proapoptotic UPR arm becomes more active $[132,153]$. Ageing deteriorates expression and the kinase activity of the endoplasmic reticulum stress sensor PERK and impairs cytoprotective eIF2 $\alpha$ phosphorylation, thereby permitting protein translation and proapoptotic protein expression in the endoplasmic reticulum under ageing conditions [153, 154]. In agreement, Chop expression levels increases in various organs with age $[132,153,155]$. In ageing lungs, endoplasmic reticulum stress and UPR genes were not altered in global transcriptome studies [138], but protein levels of the endoplasmic reticulum chaperones Grp78 were reduced, while Grp94 and proapoptotic Chop were concertedly upregulated in AECII cells of ageing lungs [133].

\section{Dysregulation of proteasome system}

The proteasome system is key to cellular proteostasis in ageing as it degrades old and damaged proteins [156]. Mild oxidative stress results in the adaptive activation of proteasomal degradation, whereas at higher oxidant levels proteasomal degradation decreases [157]. In such stress conditions, the misfolded/damaged proteins accumulate in non-degradable aggregates which are dispersed in the cytosol and are able to bind to the proteasome, and which makes the degradation of other misfolded proteins less efficient. Moreover, the proteasome itself is affected by oxidative stress. It has been shown that reactive aldehydes produced during the oxidation of carbohydrates (e.g. glyoxal, methylglyoxal) and lipids (e.g. 4-HNE, malondialdehyde) are able to cause oxidative adduct formation on several $20 \mathrm{~S}$ proteasomal subunits which consequently leads to impaired proteasome function $[125,158,159]$. In agreement, the activity of the proteasome system is impaired during ageing, while activation of the proteasome system promotes longevity [160-162]. It has been shown that during proliferative senescence of human MRC-5 fibroblasts the proteasome activity declines while the level of oxidised proteins increases [163]. In vivo studies with rats also revealed that proteasome activity declines in several tissues (brain, liver, lung, muscle and heart) during ageing [164]. Healthy ageing of the lung in mice, however, had neither altered expression of the proteasome nor of the main catalytic activity, i.e. the chymotrypsin-like activity of the proteasome [165]. In contrast, the immunoproteasome, an alternatively composed $20 \mathrm{~S}$ proteasome containing a set of inducible catalytic subunits, was significantly increased in aged versus young mice [166]. These results are of particular interest, because immunoproteasomes are usually known to be induced under conditions of viral/bacterial infection or interferon- $\gamma$ stimulation, in which they generate specific peptides that have a 
higher affinity to major histocompatibility complex (MHC) class-I mediated antigen presentation, thereby contributing to the efficient elimination of infected cells and an improved immune responses [167]. Moreover, immunoproteasomes have also been proposed to play a protective role against oxidative stress through degradation of oxidised misfolded proteins, which is, however, still a matter of debate [168-171]. Of note, the immunoproteasome is apparently not activated by NRF2 in response to ROS, as neither Nrf2 inducers nor Nrf2 inhibitors altered immunoproteasome expression [95]. Very recent studies in healthy aged mice unequivocally indicate that immunoproteasome induction in ageing lungs is associated with a prominent activation of the adaptive MHC class-I related immune responses and interferon signalling [172].

\section{Dysregulation of autophagy-lysosome pathway}

Growing evidence indicates that autophagy activity declines with age [124] as the rate of autophagosome formation and maturation and the efficiency of autophagosome/lysosome fusion are reduced in aged tissues [173]. The so-called autophagy-related (ATG) proteins are central to this process, as they regulate different steps during autophagosome biogenesis, i.e. vesicle nucleation, autophagosomal membrane elongation, and autophagosome completion [124]. In mammals, the conversion of microtubule-associated proteins 1A/1B light chain 3B (LC3B) from LC3B-I (free form) to LC3B-II (membrane-bound form, recruited to autophagosomal membranes) is regarded as a key step in the induction of autophagy. The expression of some autophagy-associated genes, including LC3B, ATG5 and ATG7, and beclin-1, declines during ageing in various tissues in humans and rodents [174, 175]. KHALI et al. [175] observed that the promoter regions of Atg5 and Map1lc3b (LC3B) are hypermethylated in macrophages from aged, but not young $\mathrm{C} 57 \mathrm{Bl} / 6 \mathrm{~J}$ mice, which was accompanied by low gene and protein expression of both autophagy markers in macrophages, as well as whole lung tissue of aged mice. Importantly, the lack of a single Atg is sufficient to abort the completion of autophagosomes [124]. Thus, intracellular accumulation of multiprotein aggregates and damaged organelles due to compromised autophagy is common during physiological ageing. Of note, aggregates collected from spleen protein lysates of aged mice revealed $>90 \%$ of carbonylated proteins, underscoring again the relevance of oxidative stress (and oxidatively damaged proteins) for increased protein aggregation and challenging the autophagy-lysosomal system [176]. Autophagy plays also an essential role in the clearance of damaged mitochondria (mitophagy), and compromised autophagy leads to mitochondrial dysfunction, accumulation of abnormal mitochondria and in turn oxidative stress [177]. The expression of PTEN-induced putative kinase 1 (PINK1), which has an important role in the maintenance of mitochondrial function and in the selective degradation of damaged mitochondria by mitophagy, is reduced in lungs of aged mice [177].

\section{Decline in proteostasis by cigarette smoke and in COPD \\ Dysregulated chaperone expression and activity}

In a comparative proteome analysis, KELSEN et al. [178] demonstrated that lungs of middle-aged smokers exhibit significant upregulation of the endoplasmic reticulum chaperones GRP78, PDI and calreticulin, as compared to age-matched ex- and nonsmokers. In another study, increased levels of GRP78 have been reported in BAL fluid of middle-aged smokers compared to age-matched never-smokers [179]. Several HSPs, including HSP10, HSP40 and HSP60, were increased in lung biopsies from COPD patients as compared to aged-matched nonsmokers and smokers with normal lung function, and in particular HSP60 level were expressed in neutrophils and positively correlated with elevated numbers of neutrophils in COPD patients [180]. Furthermore, "global" expression of HSP70 was observed to be upregulated in peripheral lung tissue of COPD patients, and positively correlated with the severity of the disease [181]. Serum levels of HSP27, HSP70 and HSP90 were also elevated in COPD patients and may serve as diagnostic markers for COPD [182].

Taken together, inducibility of endoplasmic reticulum and HSP chaperones is not impaired in the aged, stressed COPD lung, and may by triggered by environmental (excessive) ROS or other stress-stimuli; but their function is presumably compromised, as they are progressively oxidised under conditions of ageing and $\operatorname{ROS}[134,135,183]$.

\section{Endoplasmic reticulum stress}

Induction of endoplasmic reticulum stress including $\mathrm{CHOP}$ has been observed in different cell types of end-stage COPD lung tissue (Global Initiative for Chronic Obstructive Lung Disease (GOLD) III/IV), but not in age-matched GOLD0, GOLD1 and GOLD2 patients [184]. Isolated fibroblasts from end-stage COPD patients displayed disorganised endoplasmic reticulum, Golgi and lysosomal structures and a tendency of increased caspase- 3 activation in comparison to fibroblasts obtained from age-matched healthy smokers and never-smokers [185]. The induction of the UPR in COPD lungs has been linked to oxidative stress induced by chronic exposure to cigarette smoke [51]. In agreement, cigarette smoke induced a proapoptotic endoplasmic reticulum stress response in HBE cell lines preferentially by two 
branches of the UPR, namely through the PERK/eIF2 $\alpha$ - and the ATF6-pathways, with upregulation of GRP78, phospho-eIF2 $\alpha$, ATF4 and CHOP [186, 187]. Similarly, increased endoplasmic reticulum stress involving Chop has also been observed in mice exposed to cigarette smoke for 3 months [186, 187]. Interestingly, some reports document the induction of a rather protective UPR in airway epithelial cells in response to $24 \mathrm{~h}$ exposure to CSE, with specific upregulation of endoplasmic reticulum chaperones, adaptive ATF4 genes, and increases in NRF2 and antioxidant genes, but no activation of proapoptotic UPR genes [178, 188]. GeRAGHTy et al. [189] observed that mice exposed to acute levels of cigarette smoke for 4 weeks developed only minimal lung destruction and exhibited only slightly elevated levels of Chop, while long-term chronic CSE for 1 year resulted in emphysema-like tissue destruction with reduced levels of Atf4 and Chop. Interestingly, protein levels of Grp78 were increased both in acute and chronic cigarette smoke-exposed mice [189]. These in vivo data indicate that chronic cigarette smoke is not sufficient to induce proapoptotic endoplasmic reticulum stress and/or COPD-like pathogenesis, but possibly involves additional detrimentally acting environmental as well as endogenous factors. Dysregulated NRF2-signalling and lack of antioxidants in old individuals $[8,9]$ may predispose to a proapoptotic UPR response induced by cigarette smoke. Similarly, viral and bacterial infections which are well-known inducers of endoplasmic reticulum stress, may amplify existing stress in elderly COPD patients and contribute to pro-apoptotic UPR [190]. The specific contribution of endoplasmic reticulum stress to the pathogenesis of COPD, however, remains to be systematically studied.

\section{Defective proteasome function}

Several studies in the past reported impairment of standard proteasome activities by acute cigarette smoke exposure in lung epithelial cells in vitro and in lung tissue of mice in vivo [184, 191, 192]. In contrast, chronic exposure of mice to cigarette smoke (4 months) rather activated proteasome expression and activity, possibly as part of an adaptive stress response [193]. The effect of cigarette smoke on the proteasome in aged mice has not been investigated so far. In a mouse model of experimentally reduced proteasome function, CSE accelerated emphysema-like lung destruction, suggesting that reduced proteasome function is a key driver of COPD pathogenesis [194]. In line with this observation, both standard and immunoproteasome activities are strongly impaired in end-stage COPD lung tissues, and immunoproteasome expression was specifically downregulated in total BAL cells and isolated alveolar macrophages of COPD patients [193]. These results suggest impaired MHC class I-mediated antigen presentation of viral or bacterial antigens to $\mathrm{CD} 8^{+} \mathrm{T}$-cells in $\mathrm{COPD}$, possibly contributing to impaired clearance of pathogens, sustained infections and exacerbations in the aged COPD patients. Impaired proteasome function in end-stage COPD is in agreement with the results by MiN et al. [184] who found abnormal accumulation of ubiquitinated (misfolded) proteins concomitantly with aggregation markers widely spread in overall lung tissue of GOLDIII and GOLDIV COPD patients. Thus, it appears that COPD patients, in contrast to mice, have lost their adaptive capacity to activate the proteasome system to cope with the elevated levels of (misfolded) oxidatively modified proteins.

\section{Activation of autophagy}

Notably, lungs of COPD patients display a remarkable activation of autophagy [195]. Markers of autophagy, such as the ratio of LC3B-II/LC3B-I, as well as the expression of ATG proteins ATG4B, ATG5-ATG12 and ATG7, were significantly enhanced in COPD lungs from all stages, including GOLD0, when compared to lungs from age-matched nonsmokers [195]. Electron microscopy, a gold standard for determination of autophagy, revealed that autophagic vacuoles were dramatically increased in COPD lung tissues from all stages, whereas little vacuole formation was evident in control tissues [195]. Widespread apoptosis in GOLD3/4 COPD lungs, as observed by many research groups [42, 79, 195], could be the cause of autophagic cell death due to "excessive autophagy" which has been associated with degradation and consumption of bystander normal cellular constituents [196].

Furthermore, increased autophagy has been clearly demonstrated as a general response to CSE in rodent lungs or epithelial cells [195, 197]. Exposure of primary HBE cells to CSE triggered dose- and time-dependent accumulation of the active form of LC3B, LC3B-II, increased autophagosome formation and was accompanied by induction of apoptosis markers [195, 197, 198]. Similarly, lungs of C57Bl/6J mice exposed to cigarette smoke for 4 months indicated increased accumulation of active LC3B-II and apoptosis markers [197]. In contrast, mice with global deficiency of LC3B (Map1lc3b $b^{(-/-)}$mice) were protected from epithelial apoptosis and cigarette smoke-induced airspace enlargement, suggesting a pivotal role of LC3B in cigarette smoke-induced apoptosis and emphysema formation [197]. Moreover, cigarette smoke-induced autophagy in wild-type mice involved extensive cilia consumption and shortening, thereby contributing to mucociliary dysfunction in bronchial cells. Mice with impaired autophagy $\left(\mathrm{Becn}^{(+/-)}\right.$or Map1lc3b ${ }^{(-/-)}$ mice) resisted cigarette smoke-induced cilia shortening [196]. In addition, increased mitophagy and necroptosis contributed to cigarette smoke-induced epithelial cell death and emphysema development in 
mice [199]. In accordance, the expression of mitophagy marker PINK1 was upregulated in bronchial epithelial cells, as well as whole lung tissue of COPD patients [199, 200]. While induction of autophagy might initially be part of an adaptive stress response to cope with misfolded and accumulating proteins upon oxidative stress, insufficient autophagic clearance may take place as indicated by in vitro experiments with CSE treated primary HBE cells isolated from COPD patients and normal HBE cells, where accumulation of p62 and ubiquitinated proteins, both indicators of insufficient autophagic clearance was observed at later time-points of CSE exposure [201]. In light of documented "excessive autophagy and apoptosis in COPD lungs", these additional data indicate that protective autophagy appears to be absent in COPD, presumably due to excessive ROS overwhelming the autophagy-lysosomal system.

Taken together, the proteostasis system is severely imbalanced in COPD, with activation of chaperones, the UPR and autophagy but impairment of the proteasomal protein degradation pathway.

\section{Impaired proteostasis in IPF \\ Dysregulated chaperone expression and activity}

Several studies demonstrated increased expression of various HSP and endoplasmic reticulum chaperones in IPF lung tissue, with localisation in fibroblast foci, abnormal bronchiolar epithelium and/or AECII [202-205]. The multifunctional HSP90 chaperone is upregulated in fibroblast foci and abnormal bronchiolar epithelium, as well as AECII of IPF patients. HSP90 acts as a crucial mediator of TGF- $\beta 1$ signalling in fibrotic lung diseases, and inhibition of HSP90 by the small molecule 17-AAG (17-allylamino-17-demethoxygeldanamycin) prevented myofibroblast transdifferentiation in response to TGF- $\beta 1$ exposure from both fibroblasts and AECII-like A549 cells in vitro and in bleomycin-challenged mice in vivo [202]. Induction and upregulation of HSP27 in abnormal bronchiolar basal cells of IPF lungs might promote their exaggerated proliferation and migration during the aberrant bronchiolisation process of damaged alveoli in IPF [203, 204]. In contrast, both the major inducible (HSP72) and constitutive (HSC70) isoforms of HSP70 are reduced in cultured IPF-fibroblasts in vitro and in fibrotic areas of IPF-lungs in vivo as compared to normal lungs from age-matched donors [206]. TGF- $\beta 1$ suppressed HSP70 protein expression in primary human lung fibroblasts and homozygous $H s p 70^{(--)}$knockout mice revealed accelerated development of lung fibrosis in response to bleomycin compared to wild-type control animals [206]. Vice versa, overexpression of Hsp70 in transgenic mice protected against bleomycin-induced lung fibrosis [207].

The endoplasmic reticulum chaperone GRP78 is upregulated in AECII and overall lung tissue of old IPF patients versus age-matched organ donors, concomitantly with other markers of endoplasmic reticulum stress $[204,205,208,209]$. Of note, alveolar epithelial GRP78 upregulation in sporadic IPF does not differ from familial IPF associated with SFTPC mutations [205] which are reported to result in misfolding and aggregation of the mutant SP-C proprotein [205]. However, there might be context-specific regulation as BOROK et al. [133] observed downregulation of GRP78, but concomitant upregulation of GRP94 in AECII of IPF patients as compared to AECII from age-matched donors. Mice with conditional AECII-specific knockout of Grp78 developed lung fibrosis similar to human IPF after 2 weeks following tamoxifen treatment, with increased susceptibility of aged and male mice [133].

Taken together, it appears that the inducibility of some HSP and endoplasmic reticulum chaperones in response to stress is not impaired in the ageing lung under conditions of IPF, but their function is presumably compromised due to increased protein oxidation $[134,135,140,141]$.

\section{Activation of endoplasmic reticulum stress}

A growing body of evidence implicates a non-adaptive pro-apoptotic endoplasmic reticulum stress response which largely involved CHOP as a critical mediator of AECII apoptosis upon injury in both sporadic and familial IPF pathogenesis $[133,204,205,208,210-212]$, thus representing a common pathomechanistic principle. In familial cases, this may be caused by mutations in the surfactant protein (SP)-C (SFTPC) and SP-A2 (SFTPA2) genes, which cause misfolding of SP-C and SP-A2 proteins, respectively [205, 213-215]. In sporadic cases the reasons are as yet unclear, but various conditions such as oxidative stress, DNA-damage, ageing, protein overload, viral infections and expression of damaged/mutant proteins may well contribute to protein damage and misfolding, and thus endoplasmic reticulum stress and UPR induction, with AECII being primarily affected [18, 216, 217]. IPF AECII show increased levels of oxidative stress and protein oxidation [104, 112], proteostasis imbalance, genomic instability, telomere attrition [117, 118], deregulated nutrient sensing and mitochondrial dysfunction [18, 177] which are all potent endoplasmic reticulum stress stimuli. This may all (together) contribute to non-adaptive proapoptotic endoplasmic reticulum stress in AECII in the presence of "second hits", especially in the more common sporadic form of IPF without genetic predisposition. In accordance, old C57Bl/6J mice (aged $>18$ months), but not young mice (aged 2 months) develop lung fibrosis that is associated with increased AECII endoplasmic reticulum stress and apoptosis when challenged with murine $\gamma$-herpesvirus 68 [218]. 
As outlined above, aged mice with an inducible AECII-specific knockout of Grp78 are highly sensitive to endoplasmic reticulum stress-mediated AECII apoptosis and lung fibrosis compared to young knock-out mice [133]. The tight interconnection between oxidative stress and endoplasmic reticulum stress in IPF pathogenesis is supported by the reported increases in protein oxidation in IPF AECII $[104,112]$ and the fact that antioxidants reduce endoplasmic reticulum stress and improve protein secretion in an in vitro model of protein misfolding [219]. Moreover, it was demonstrated that direct administration of glutaredoxin into airways in mice with TGF- $\beta 1$ - or bleomycin-induced lung fibrosis reduced protein oxidation and attenuated collagen deposition and fibrosis, even when administered to fibrotic, aged mice [112]. Aerosolised administration of the glutathione precursor $\mathrm{N}$-acetyl-L-cysteine also attenuated bleomycin-induced lung fibrosis in mice [220]. All these results support the suggestion that the lack of antioxidant capacity observed in aged individuals $[8,9]$ and patients with IPF $[86-89,96]$ also contributes to endoplasmic reticulum stress induction. In addition, DNA damage, genomic instability and aberrant DNA repair induced by shortened telomeres may also cause proteotoxicity through translation of aberrant proteins and consecutive UPR activation in IPF AECII [216, 221]. It is also intriguing to speculate that oxidative stress and defective telomere maintenance in the IPF AECII affects surfactant production and processing of hydrophobic surfactant proteins in these cells $[101,216]$.

In contrast to proapoptotic endoplasmic reticulum stress in IPF AECII, various studies document that (prosurvival acting) adaptive UPR mechanisms mediated by the ATF6 $\alpha$ - and the IRE1 $\alpha / \mathrm{XBP} 1$ branch in IPF fibroblasts contribute directly to fibrogenesis and ECM production, involving upregulation of endoplasmic reticulum chaperones. GRP78 and XBP1 are significantly overexpressed in myofibroblasts of fibroblast foci in IPF $[209,222]$. Similarly, ATF6 $\alpha$, XBP1, GRP78 and calreticulin are upregulated during TGF- $\beta$-induced myofibrobast differentiation of primary mouse and human lung fibroblasts [209, 223225], whereas apoptotic endoplasmic reticulum stress indicators are not induced [209]. RNAi mediated depletion of GRP78 or calreticulin abrogates TGF- $\beta$-induced ECM production in mouse, rat and human IPF fibroblasts $[209,223]$. A more recent study by GHAVAmi et al. [222] describes that the adaptive IRE1 $\alpha /$ XBP1 pathway as well as autophagy promote the profibrotic effects of TGF- $\beta 1$ in isolated IPF fibroblasts ex vivo. It is well-known that the UPR may induce cytoprotective autophagy under constant endoplasmic reticulum stress, through the PERK/ATF4 branch [139, 226, 227] and the IRE1 $\alpha / \mathrm{XBP} 1$ arm [228], to support the degradation of "unwanted" proteins and non-functional organelles to maintain endoplasmic reticulum homeostasis. In line with these observations, TGF- $\beta 1$-induced autophagy and ECM production is abated by inhibiting IRE1 $\alpha$ activity [222]. It thus appears that an adaptive endoplasmic reticulum stress response takes place in contractile protein-expressing myofibroblasts, aiming to maintain endoplasmic reticulum proteostasis under conditions of elevated ECM protein production.

Altered proteasome function

In IPF fibrotic lungs, the expression and activity of the proteasome system is generally activated [204, 229, 230], while expression of the $11 \mathrm{~S}$ proteasome regulator PSME1, which is involved in degradation of oxidised proteins, is decreased in IPF $[95,96]$. Protein degradation of damaged proteins appears to be impaired especially in AECII of IPF patients with familial SFTPC mutations. Overexpression of misfolded BRICHOS mutant SP-C proteins leads to the formation of SDS-insoluble proSP-C macroaggregates in vitro and intracellular amyloid/aggresome formation in vivo [213, 214, 231]. It was associated with defective ERAD and impaired proteasome function [214, 231]. Defective protein degradation is also suggested in AECII of sporadic IPF patients, where increased ROS and protein oxidation occur concomitantly with impaired detoxifying mechanisms $[96,104,112]$. Defects in surfactant processing in IPF AECII $[101,216]$ together with the propensity of the very hydrophobic SP-B and SP-C proteins to form $\beta$-amyloid structures [232] might contribute to the observed upregulation of endoplasmic reticulum and cytosolic chaperones such as GRP78, PDIA4, HSP90ß, Hsc70/Hsp90-organising protein and the ERAD component valosin-containing protein (VCP) in these cells [204]. VCP is involved in the export of polyubiquitinated misfolded proteins from the endoplasmic reticulum to the cytoplasm for degradation by the $26 \mathrm{~S}$ proteasome [233]. VCP is also found in non-degradable polyubiquitinated substrates and abnormal multiprotein aggregates [234, 235]. The abnormal increase in VCP levels in AECII of IPF lungs might thus reflect an impairment of proteasome function in this highly secretory cell-type [204]. On the contrary, collagen-producing IPF fibroblasts/myofibroblasts rely on an increased activity of the $26 \mathrm{~S}$ proteasome to cope with activated protein turnover [230]. Such activation in proteasomal protein degradation accords very well with the above described pro-survival activity of the adaptive UPR in ECM producing myofibroblasts [209, 222, 223].

Defective autophagy

Autophagy is impaired in lungs of IPF patients as indicated by reduced levels of autophagy markers and rare occurrence of autophagosomes, although the underlying mechanisms have not yet been identified 
[236, 237]. In agreement, immunohistochemical evaluation of IPF lung tissue revealed increased level of polyubiquitinated proteins and p62, both markers of insufficient autophagy, in epithelial cells as well as fibroblastic foci [237]. Aggregation markers, such as VCP (see above), are upregulated in AECII and whole lung tissue of IPF lungs [204], suggesting defective clearance by impaired autophagy. Insufficient autophagic clearance of misfolded proteins may also contribute to endoplasmic reticulum stress-induced apoptosis of IPF AECII, a critical event in IPF pathogenesis [208, 210-212]. Accordingly, activation of autophagy by the well-known mTOR (mammalian target of rapamycin) inhibitor rapamycin in mice was demonstrated to attenuate bleomycin-induced lung fibrosis in two independent studies [238, 239]. Furthermore, IPF AECII suffering from endoplasmic reticulum stress also exhibited marked accumulation of dysmorphic and dysfunctional mitochondria and lack of PINK1, indicative of defective mitophagy. Moreover, PINK1 ${ }^{(-/-)}$deficient mice developed similarly dysmorphic, dysfunctional mitochondria in the AECIIs and were vulnerable to apoptosis and development of lung fibrosis [177].

Interestingly, the role of autophagy in fibrotic lung fibroblasts/IPF fibroblasts is controversial. On the one hand, it has been demonstrated that TGF- $\beta 1$-mediated mTOR activation and concomitant autophagy inhibition was required for myofibroblast differentiation in normal human MRC-5 lung fibroblasts, as rapamycin reversed this effect and blocked myodifferentiation [236]. On the other hand, ARAYa et al. [237] showed increased autophagy and ECM protein production in primary normal lung fibroblasts in response to TGF- $\beta 1$ treatment, which was augmented by siRNA mediated knockdown of the autophagy-related genes MAP1LC3B and ATG5 in the presence of TGF- $\beta 1$. Of interest, in cardiac fibrosis, autophagy appeared to be required for fibroblast to myofibroblast phenoconversion, as autophagy was induced by TGF- $\beta 1$ and inhibition of autophagy by bafilomycin-A1 or chloroquine repressed the fibrogenic response of cardiac fibroblasts [240, 241]. In agreement with a profibrotic role of autophagy in lung fibroblasts, GHAvami et al. [222] recently reported that TGF- $\beta 1$ activated IPF fibroblasts trigger the IRE1 $\alpha /$ XBP1-UPR-arm for induction of autophagy to enable the excessive biosynthesis of ECM proteins in the endoplasmic reticulum. Inhibition of IRE1 $\alpha$ activity abated the profibrotic effect of activated autophagy in this model, underscoring the crucial interplay of endoplasmic reticulum stress and autophagy in IPF [222].

In conclusion, IPF lungs show signs of severely disturbed proteostasis such as elevated endoplasmic reticulum stress and proteasome function but defective autophagy.

\section{Cellular senescence}

The cellular programme of senescence is characterised by the irreversible cell cycle arrest in response to cellular ageing and telomere attrition, oncogenic signalling and stress stimuli, including cytokines, ROS (e. g. cigarette smoke) or DNA damage [242]. This latter form of senescence is also known as stress-induced premature senescence [243]. In contrast to apoptotic cells, senescent cells are metabolically active and may affect neighbouring cells via secretion of multiple inflammatory proteins (IL-1 $\beta$, IL-6, TNF- $\alpha$, IL-8, monocyte chemoattractant protein-1), ROS molecules and ECM-degrading enzymes including matrix metalloproteinases (MMPs), which is described as the senescence-associated secretory phenotype (SASP) [244]. Markers for cellular senescence include increased expression of cell-cycle regulators and tumour suppressors $\mathrm{p} 53, \mathrm{p} 21^{\mathrm{Cip} 1}$, and $\mathrm{p} 16^{\mathrm{INK} 4 \mathrm{a}}$, as well as upregulation of $\beta$-galactosidase activity. While the p53/ p2 ${ }^{\mathrm{CIP} 1}$ pathway seems to play a key role in the initiation of senescence upon DNA damage stress [31], the pathway involving p16 and the retinoblastoma family of proteins ( $\mathrm{Rb}$ family) appears to have a central role in the maintenance of senescence [245]. Although cellular senescence exhibiting SASP has been considered to protect against tumorigenesis and cancer [246], accumulation of senescent cells over time in ageing mammals affects tissue regenerative capacity and leads to tissue dysfunction and frailty, thereby shortening life span [247].

\section{Cellular senescence in COPD}

In support of the concept of accelerated lung ageing in COPD, there is evidence for the accumulation of senescent cells in lungs from patients with COPD [248, 249]. Increased levels of senescence-related markers $\beta$-galactosidase, p21 and p16 are observed in numerous cell-types of COPD lungs, including AECII, smooth muscle and endothelial cells and fibroblasts, as compared to age-matched non-COPD controls [248-252]. The senescence phenotype in COPD epithelial cells has been found to be associated with a robust inflammatory SASP repertoire [253]. Senescence of COPD fibroblasts was also linked with abnormal high expression of proinflammatory mediators, dysregulated ECM protein production, decreased contractility and migration, reduced TGF- $\beta 1$ responsiveness, and an overall impaired repair capacity [254-256]. It is hypothesised that in COPD senescent epithelial and mesenchymal cells with the secretion of proinflammatory SASP factors contribute to chronic inflammation, tissue destruction and emphysema, and impaired wound healing processes in the lung $[248,253,256]$. Of note, in an experimental model of induced cellular senescence by global genetic or lung epithelial cell-specific ablation of p16INK4a p16, mice were not protected from emphysema development, inflammation, and deterioration of lung function when exposed to chronic cigarette 

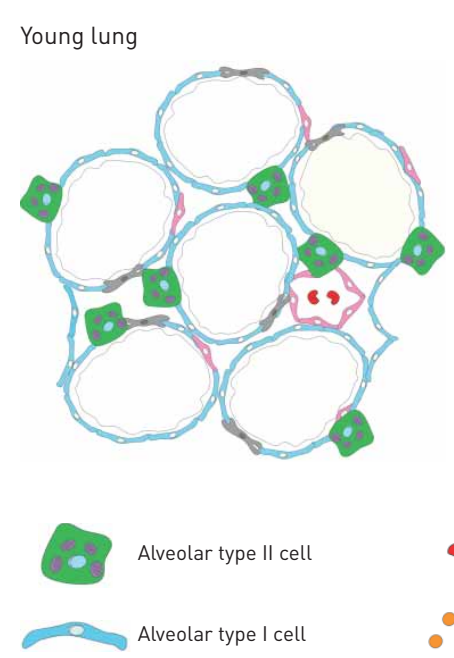

$\odot$
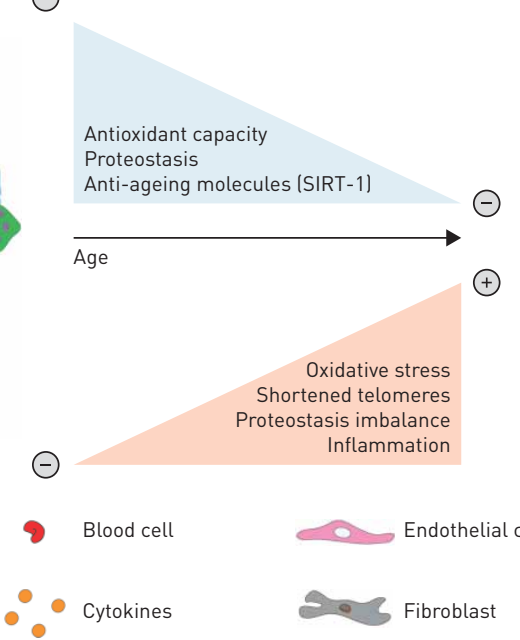

Aged lung

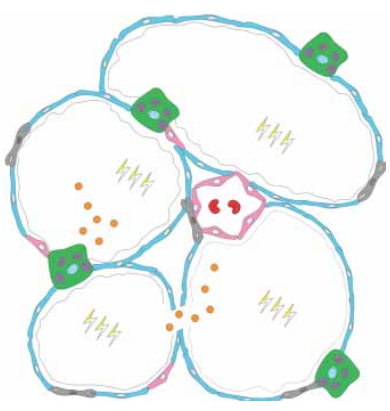

Oxidative stress

FIGURE 2 Pathogenesis of lung ageing. The decline of major components of overall adaptive homeostasis capacity (e.g. antioxidant defences and proteostasis capacity) during ageing increases oxidative stress which further exerts detrimental effects on genomic integrity and proteostasis, leading to a progressive deterioration of pulmonary function and a pro-inflammatory shift. This is accompanied by a structural change designated "senile emphysema", which is characterised by reduced proliferation of alveolar/septal wall cells and eminent enlargement of the alveolar airspaces without alveolar wall destruction.

smoke or elastase [257]. These results indicate that this pathway of cell senescence might not be causal for the development of experimentally induced lung emphysema. However, numerous reports have demonstrated a role for senescence in COPD development [258-260], and chronic exogenous and endogenous oxidative stress is considered as a key driver of cellular senescence in COPD [260]. "Senotherapies" are currently suggested for COPD treatment, either by inhibiting the pathways that lead to cellular senescence (senostatics) or by deleting senescent cells (senolytics) [260, 261]. Senolytic drugs remove senescent cells though induction of apoptosis while having no or little effect on proliferating cells [260]. The combination of dasatinib, a tyrosine kinase inhibitor, and the polyphenol quercetin (both acting as senolytics) reduced the numbers of senescent cells, p16 expression, and the SASP-response in elderly mice and restored age-related cardiovascular changes [262]. For detailed information, the reader is referred to the recent reviews on senotherapies in age-related diseases as well as their potential use as future therapeutic options in COPD [260, 261, 263].

\section{Cellular senescence in IPF}

Some studies have suggested that accumulation of senescent epithelial cells and fibroblasts contribute to the fibrogenic process in experimental lung fibrosis and human IPF via the action of SASP mediators [217, 264, 265]. These studies demonstrated attenuation of bleomycin-induced lung fibrosis in vivo by depletion of senescent cells using senolytic drugs such as dasatanib and quercetin [264, 265], as well as in tissue cultures of fibrotic mouse lungs ex vivo [217]. It was also shown that the stress-induced SASP of irradiated senescent IMR90 lung fibroblasts and that of senescent AECII isolated from bleomycin injured lungs are fibrogenic, as it exhibited amongst others increased levels of IL-6, MCP-1, MMP12, PAI-1 and TGF- $\beta 1$ [217, 264]. However, two contrary reports also exist which report resolution and attenuation of lung fibrosis in bleomycin mice by lung fibroblast senescence $[266,267]$. In agreement, myofibroblast senescence has been widely documented to play important roles in fibrosis resolution in the liver, skin, heart and kidney [268, 269]; and the SASP of liver and skin myofibroblasts included reduced levels of collagen-I and TGF- $\beta 1$ [269, 270]. In support of a cell-type specific role of senescence, it was shown by two independent research groups that systemic induction of telomere attrition (a well-known driver of cellular senescence) in AECII, but not mesenchymal cells, contributed to lung remodelling and fibrosis in mice [271, 272]. This notion is further supported by the regional expression patterns of established senescence markers in IPF lungs. Although increased expression of $\beta$-galactosidase, p53, p21 and p16 has been reported in some studies in both fibroblasts and AECII of IPF lung tissue [217, 264, 273-276], other reports document significantly lower level of basal p53 in cultured IPF fibroblasts or no detection of p16 or p21 in fibroblasts, as well as in fibroblast foci of IPF lungs [237, 277, 278]. Furthermore, the reported upregulation of cancer-associated class-I HDAC enzymes in IPF fibroblasts, in particular HDAC2 [279], preclude the existence of high p21 level in this cell-type, since HDAC2 inhibits p53 transcriptional activity through deacetylation and represses $221^{\text {Cip } 1}$ expression [280]. Moreover, telomere attrition has been observed in AECII, but not fibroblasts of IPF lungs, and both in sporadic as well as familial IPF cases associated with ubiquitous TERT and TERC mutations [117, 118]. LEHMANN et al. [217] demonstrated 


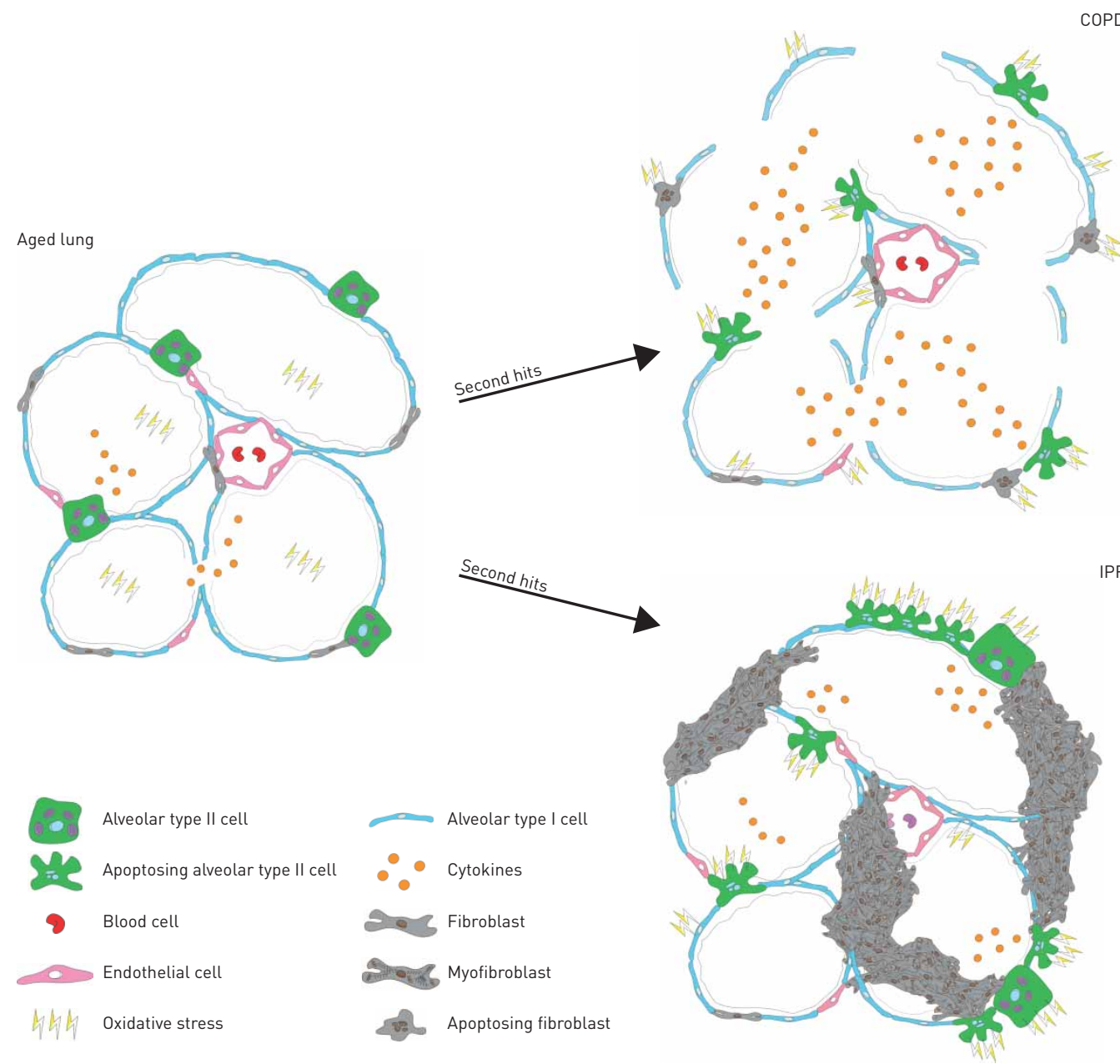

FIGURE 3 Predisposition of the aged lung to chronic lung diseases such as COPD or idiopathic pulmonary fibrosis (IPF). The vulnerable aged lung is primed to oxidative stress, cell injury and disrepair, acting as the "first hit". Environmental challenges such as cigarette smoking, air pollution or viral/bacterial infections may serve as "second hits" which worsen age-related events and contribute to persistently elevated oxidative stress levels, that overwhelms the (weakened) defence and repair pathways. Whereas increased demise of type-II alveolar epithelial cells (AECII) is a common feature in both diseases, in COPD, however, oxidative stress and its detrimental consequences also result in a loss of structural fibroblasts and septal endothelial cells, leading to an irreversible loss of lung tissue and progressive formation of emphysematous spaces. In IPF, death and loss of AECII triggers abnormal fibroblast proliferation, myofibroblast differentiation and irreversible scar tissue generation, with oxidative stress contributing to this process. The "origins" that predispose the ageing lung to develop either COPD or IPF after the decisive injury, remain elusive.

that epithelial cells, in particular AECII, represent the major cell type that is affected by senescence in fibrotic lungs of bleomycin-treated mice as well as IPF-patients, and that profibrotic SASP factors released by senescent AECII of bleomycin mice contribute to the proliferation of neighbouring fibroblasts thus contributing to pulmonary fibrosis. A more recent study demonstrated that p53-induced AECII senescence was able to drive the development of pulmonary fibrosis in mice, and highlighted the importance of senescent AECII as a source of TGF- $\beta$ and the driving force of epithelial TGF- $\beta$ for fibroproliferation [281]. However, the SASP of senescent cells does not appear to be the sole driving force for the development of human IPF. It must not be ignored that loss of AECII and alveolar stem cell depletion per se represent a critical determinant of IPF. It is still a matter of ongoing research, how senescence contributes to IPF pathogenesis. As outlined in this review, other hallmark mechanisms of ageing, such as endoplasmic reticulum stress and oxidative stress, defective proteostasis and mitochondrial dysfunction also contribute to IPF, through demise of AECII (by cell death) and consecutive loss of alveolar progenitors.

Despite the promising results of senolytic drugs in preclinical studies [264, 265], as well as from a small phase 1 study in IPF patients using dasatanib and quercetin [282], the use of senolytics as a therapeutic option for the treatment of IPF should be carefully reconsidered, because not every cell type and every type of senescence seems to be affected by these drugs [283]. 


\section{Conclusion}

In conclusion, the summarised data provide strong evidence that the age-related decline in redox and proteostasis balance is a major contributing factor to oxidative stress and impaired proteostasis in COPD and IPF. Oxidative stress is indeed one of the central effector pathways which affects several of the ageing pathways, such as genomic instability, telomere attrition, loss of proteostasis, mitochondrial dysfunction and cellular senescence. The stress-induced senescence programme as outlined above may also represent a proxy to further spread cellular damage and activate the immune system.

In COPD and IPF, both the age-dependent decline of central quality control and antioxidant defence mechanisms and the resulting induction of oxidative stress might represent a "first hit" that renders lungs susceptible to injury and disease. Altered lung development may further add to this process. Environmental insults such as smoking, air pollution and/or infections appear to serve as "second hits" which contribute to persistently elevated oxidative stress levels, that overwhelm the (weakened) adaptive defence and repair pathways, thereby promoting respiratory disease development.

It is thus obvious that the steady impairment of protective and adaptive stress responses in the ageing lung causes a different response to additional stress than in the young lung (figure 2). We propose that at some point the balance towards detrimental stress responses is tipped which will then promote an avalanche of detrimental reactions that contribute to development of respiratory diseases, such as COPD or IPF (figure 3). While there are obvious differences in the cell-specific regulation of adaptive stress responses in COPD and IPF (as outlined above) the particular mechanisms that drive one or the other disease still remain elusive. Nevertheless, it is clear from this review that treatment options for COPD and IPF should aim for the activation of overall adaptive homeostasis capacity, such as by augmenting endogenous antioxidant defences and stabilising the proteostasis network, and the suppression of oxidative stress sources in the older patients.

Conflict of interest: None declared.

\section{References}

1 Fukuchi Y. The aging lung and chronic obstructive pulmonary disease: similarity and difference. Proc Am Thorac Soc 2009; 6: 570-572.

2 Choudhury G, MacNee W. Role of inflammation and oxidative stress in the pathology of ageing in COPD: potential therapeutic interventions. COPD 2017; 14: 122-135.

3 Babbar M, Basu S, Yang B, et al. Mitophagy and DNA damage signaling in human aging. Mech Ageing Dev 2020; 186: 111207.

4 Nomellini V, Brubaker AL, Mahbub S, et al. Dysregulation of neutrophil CXCR2 and pulmonary endothelial ICAM-1 promotes age-related pulmonary inflammation. Aging Dis 2012; 3: 234-247.

Blasco MA. Telomere length, stem cells and aging. Nat Chem Biol 2007; 3: 640-649.

Bratic A, Larsson NG. The role of mitochondria in aging. J Clin Invest 2013; 123: 951-957.

Powers ET, Morimoto RI, Dillin A, et al. Biological and chemical approaches to diseases of proteostasis deficiency. Annu Rev Biochem 2009; 78: 959-991.

8 Zhang H, Davies KJA, Forman HJ. Oxidative stress response and Nrf2 signaling in aging. Free Radic Biol Med 2015; 88: 314-336.

9 Zhou L, Zhang H, Davies KJA, et al. Aging-related decline in the induction of Nrf2-regulated antioxidant genes in human bronchial epithelial cells. Redox Biol 2018; 14: 35-40.

Issa JP. Aging and epigenetic drift: a vicious cycle. J Clin Invest 2014; 124: 24-29.

Meiners S, Eickelberg O, Konigshoff M. Hallmarks of the ageing lung. Eur Respir J 2015; 45: 807-827.

12 Raghu G, Weycker D, Edelsberg J, et al. Incidence and prevalence of idiopathic pulmonary fibrosis. Am J Respir Crit Care Med 2006; 174: 810-816.

13 van Durme Y, Verhamme KMC, Stijnen T, et al. Prevalence, incidence, and lifetime risk for the development of COPD in the elderly: the Rotterdam study. Chest 2009; 135: 368-377.

14 Chilosi M, Poletti V, Rossi A. The pathogenesis of COPD and IPF: distinct horns of the same devil? Respir Res 2012; 13: 3 .

15 Lange P, Celli B, Agusti A, et al. Lung-function trajectories leading to chronic obstructive pulmonary disease. N Engl J Med 2015; 373: 111-122.

16 Meiners S, Hilgendorff A. Early injury of the neonatal lung contributes to premature lung aging: a hypothesis. Mol Cell Pediatr 2016; 3: 24.

17 Yoshida T, Tuder RM. Pathobiology of cigarette smoke-induced chronic obstructive pulmonary disease. Physiol Rev 2007; 87: 1047-1082.

18 Martinez FJ, Collard HR, Pardo A, et al. Idiopathic pulmonary fibrosis. Nat Rev Dis Primers 2017; 3: 17074

19 Kasahara Y, Tuder RM, Cool CD, et al. Endothelial cell death and decreased expression of vascular endothelial growth factor and vascular endothelial growth factor receptor 2 in emphysema. Am J Respir Crit Care Med 2001; 163: $737-744$

20 Imai K, Mercer BA, Schulman LL, et al. Correlation of lung surface area to apoptosis and proliferation in human emphysema. Eur Respir J 2005; 25: 250-258.

21 Deslee G, Woods JC, Moore C, et al. Oxidative damage to nucleic acids in severe emphysema. Chest 2009; 135: 965-974.

22 Deslee G, Adair-Kirk TL, Betsuyaku T, et al. Cigarette smoke induces nucleic-acid oxidation in lung fibroblasts. Am J Respir Cell Mol Biol 2010; 43: 576-584.

23 Snider GL. Chronic obstructive pulmonary disease: risk factors, pathophysiology and pathogenesis. Annu Rev Med 1989; 40: 411-429. 
American Thoracic Society. Idiopathic pulmonary fibrosis: diagnosis and treatment. International consensus statement. American Thoracic Society (ATS), and the European Respiratory Society (ERS). Am J Respir Crit Care Med 2000; 161: 646-664

Selman M, Martinez FJ, Pardo A. Why does an aging smoker's lung develop idiopathic pulmonary fibrosis and not chronic obstructive pulmonary disease? Am J Respir Crit Care Med 2019; 199: 279-285.

Sies H, Berndt C, Jones DP. Oxidative Stress. Annu Rev Biochem 2017; 86: 715-748.

Rahman I, Biswas SK, Kode A. Oxidant and antioxidant balance in the airways and airway diseases. Eur $J$ Pharmacol 2006; 533: 222-239.

Braidy N, Guillemin GJ, Mansour H, et al. Age related changes in NAD+ metabolism oxidative stress and Sirt1 activity in wistar rats. PLoS One 2011; 6: e19194.

Liu Q, Gao Y, Ci X. Role of Nrf2 and its activators in respiratory diseases. Oxid Med Cell Longev 2019; 2019: 7090534 .

Hecker L, Logsdon NJ, Kurundkar D, et al. Reversal of persistent fibrosis in aging by targeting Nox4-Nrf2 redox imbalance. Sci Transl Med 2014; 6: 231 ra47.

Mijit M, Caracciolo V, Melillo A, et al. Role of p53 in the regulation of cellular senescence. Biomolecules 2020; 10: 420.

Chen QM, Liu J, Merrett JB. Apoptosis or senescence-like growth arrest: influence of cell-cycle position, p53, p21 and bax in $\mathrm{H} 2 \mathrm{O} 2$ response of normal human fibroblasts. Biochem J 2000; 347: 543-551.

Gaschler MM, Stockwell BR. Lipid peroxidation in cell death. Biochem Biophys Res Commun 2017; 482: 419-425. Ayala A, Munoz MF, Arguelles S. Lipid peroxidation: production, metabolism, and signaling mechanisms of malondialdehyde and 4-hydroxy-2-nonenal. Oxid Med Cell Longev 2014; 2014: 360438.

Pryor WA, Dooley MM, Church DF. Inactivation of human alpha-1-proteinase inhibitor by gas-phase cigarette smoke. Biochem Biophys Res Commun 1984; 122: 676-681.

Reeg S, Grune T. Protein oxidation in aging: does it play a role in aging progression? Antioxid Redox Signal 2015; 23: 239-255.

Pillai JB, Isbatan A, Imai S, et al. Poly(ADP-ribose) polymerase-1-dependent cardiac myocyte cell death during heart failure is mediated by NAD+ depletion and reduced Sir2alpha deacetylase activity. J Biol Chem 2005; 280: $43121-43130$

Hwang JW, Yao H, Caito S, et al. Redox regulation of SIRT1 in inflammation and cellular senescence. Free Radic Biol Med 2013; 61: 95-110

Nakamaru Y, Vuppusetty C, Wada $\mathrm{H}$, et al. A protein deacetylase SIRT1 is a negative regulator of metalloproteinase-9. FASEB J 2009; 23: 2810-2819.

Chen Q, Fischer A, Reagan JD, et al. Oxidative DNA damage and senescence of human diploid fibroblast cells. Proc Natl Acad Sci USA 1995; 92: 4337-4341.

Balaban RS, Nemoto S, Finkel T. Mitochondria, oxidants, and aging. Cell 2005; 120: 483-495.

$\mathrm{Wu} \mathrm{CH}$, Lin $\mathrm{HH}$, Yan FP, et al. Immunohistochemical detection of apoptotic proteins, p53/Bax and JNK/FasL cascade, in the lung of rats exposed to cigarette smoke. Arch Toxicol 2006; 80: 328-336.

Frisch SM, Screaton RA. Anoikis mechanisms. Curr Opin Cell Biol 2001; 13: 555-562.

Suzuki M, Betsuyaku T, Ito Y, et al. Down-regulated NF-E2-related factor 2 in pulmonary macrophages of aged smokers and patients with chronic obstructive pulmonary disease. Am J Respir Cell Mol Biol 2008; 39: 673-682.

Rangasamy T, Cho CY, Thimmulappa RK, et al. Genetic ablation of Nrf2 enhances susceptibility to cigarette smoke-induced emphysema in mice. J Clin Invest 2004; 114: 1248-1259.

Mercado N, Ito K, Barnes PJ. Accelerated ageing of the lung in COPD: new concepts. Thorax 2015; 70: 482-489. Kondo T, Tagami S, Yoshioka A, et al. Current smoking of elderly men reduces antioxidants in alveolar macrophages. Am J Respir Crit Care Med 1994; 149: 178-182.

Hwang JW, Rajendrasozhan S, Yao H, et al. FOXO3 deficiency leads to increased susceptibility to cigarette smoke-induced inflammation, airspace enlargement, and chronic obstructive pulmonary disease. J Immunol 2011; 187: 987-998.

Vlahos R, Bozinovski S. Glutathione peroxidase-1 as a novel therapeutic target for COPD. Redox Rep 2013; 18: 142-149.

Rahman I, van Schadewijk AA, Crowther AJ, et al. 4-Hydroxy-2-nonenal, a specific lipid peroxidation product, is elevated in lungs of patients with chronic obstructive pulmonary disease. Am J Respir Crit Care Med 2002; 166: 490-495.

Decramer M, Janssens W, Miravitlles M. Chronic obstructive pulmonary disease. Lancet 2012; 379: 1341-1351.

Church DF, Pryor WA. Free-radical chemistry of cigarette smoke and its toxicological implications. Environ Health Perspect 1985; 64: 111-126.

Jaimes EA, DeMaster EG, Tian RX, et al. Stable compounds of cigarette smoke induce endothelial superoxide anion production via NADPH oxidase activation. Arterioscler Thromb Vasc Biol 2004; 24: 1031-1036.

Orosz Z, Csiszar A, Labinskyy N, et al. Cigarette smoke-induced proinflammatory alterations in the endothelial phenotype: role of NAD(P)H oxidase activation. Am J Physiol Heart Circ Physiol 2007; 292: H130-H139.

Morrison D, Rahman I, Lannan S, et al. Epithelial permeability, inflammation, and oxidant stress in the air spaces of smokers. Am J Respir Crit Care Med 1999; 159: 473-479.

Rahman I, Morrison D, Donaldson K, et al. Systemic oxidative stress in asthma, COPD, and smokers. Am Respir Crit Care Med 1996; 154: 1055-1060.

Harijith $\mathrm{A}$, Natarajan $\mathrm{V}, \mathrm{Fu} \mathrm{P}$. The role of nicotinamide adenine dinucleotide phosphate oxidases in lung architecture remodeling. Antioxidants (Basel) 2017; 6: 104.

Rahman I. Oxidative stress in pathogenesis of chronic obstructive pulmonary disease: cellular and molecular mechanisms. Cell Biochem Biophys 2005; 43: 167-188.

Dekhuijzen PN, Aben KK, Dekker I, et al. Increased exhalation of hydrogen peroxide in patients with stable and unstable chronic obstructive pulmonary disease. Am J Respir Crit Care Med 1996; 154: 813-816.

Tzortzaki EG, Dimakou K, Neofytou E, et al. Oxidative DNA damage and somatic mutations: a link to the molecular pathogenesis of chronic inflammatory airway diseases. Chest 2012; 141: 1243-1250.

Tzortzaki EG, Siafakas NM. A hypothesis for the initiation of COPD. Eur Respir J 2009; 34: 310-315.

Zervou MI, Tzortzaki EG, Makris D, et al. Differences in microsatellite DNA level between asthma and chronic obstructive pulmonary disease. Eur Respir J 2006; 28: 472-478. 
Qiu W, Baccarelli A, Carey VJ, et al. Variable DNA methylation is associated with chronic obstructive pulmonary disease and lung function. Am J Respir Crit Care Med 2012; 185: 373-381.

Samara KD, Tzortzaki EG, Neofytou E, et al. Somatic DNA alterations in lung epithelial barrier cells in COPD patients. Pulm Pharmacol Ther 2010; 23: 208-214.

Morla M, Busquets X, Pons J, et al. Telomere shortening in smokers with and without COPD. Eur Respir J 2006; 27: 525-528.

Carnevali S, Petruzzelli S, Longoni B, et al. Cigarette smoke extract induces oxidative stress and apoptosis in human lung fibroblasts. Am J Physiol Lung Cell Mol Physiol 2003; 284: L955-L963.

Nakamura Y, Romberger DJ, Tate L, et al. Cigarette smoke inhibits lung fibroblast proliferation and chemotaxis. Am J Respir Crit Care Med 1995; 151: 1497-1503.

Bostrom H, Willetts K, Pekny M, et al. PDGF-A signaling is a critical event in lung alveolar myofibroblast development and alveogenesis. Cell 1996; 85: 863-873.

Fischer BM, Pavlisko E, Voynow JA. Pathogenic triad in COPD: oxidative stress, protease-antiprotease imbalance, and inflammation. Int J Chron Obstruct Pulmon Dis 2011; 6: 413-421.

Loukides S, Bakakos P, Kostikas K. Oxidative stress in patients with COPD. Curr Drug Targets 2011; 12: 469-477.

Domej W, Oettl K, Renner W. Oxidative stress and free radicals in COPD - implications and relevance for treatment. Int J Chron Obstruct Pulmon Dis 2014; 9: 1207-1224.

Pesci A, Majori M, Cuomo A, et al. Neutrophils infiltrating bronchial epithelium in chronic obstructive pulmonary disease. Respir Med 1998; 92: 863-870.

Dahlgren C, Karlsson A. Respiratory burst in human neutrophils. J Immunol Methods 1999; 232: 3-14.

Travis J. Structure, function, and control of neutrophil proteinases. Am J Med 1988; 84: 37-42.

Louhelainen N, Rytila P, Haahtela T, et al. Persistence of oxidant and protease burden in the airways after smoking cessation. BMC Pulm Med 2009; 9: 25.

Anderson GP, Bozinovski S. Acquired somatic mutations in the molecular pathogenesis of COPD. Trends Pharmacol Sci 2003; 24: 71-76.

Hodge S, Hodge G, Scicchitano R, et al. Alveolar macrophages from subjects with chronic obstructive pulmonary disease are deficient in their ability to phagocytose apoptotic airway epithelial cells. Immunol Cell Biol 2003; 81: 289-296.

Hodge S, Hodge G, Holmes M, et al. Increased airway epithelial and T-cell apoptosis in COPD remains despite smoking cessation. Eur Respir J 2005; 25: 447-454.

Park JW, Ryter SW, Choi AM. Functional significance of apoptosis in chronic obstructive pulmonary disease. COPD 2007; 4: 347-353.

Brusselle GG, Joos GF, Bracke KR. New insights into the immunology of chronic obstructive pulmonary disease. Lancet 2011; 378: 1015-1026.

Yao H, Edirisinghe I, Yang SR, et al. Genetic ablation of NADPH oxidase enhances susceptibility to cigarette smoke-induced lung inflammation and emphysema in mice. Am J Pathol 2008; 172: 1222-1237.

Seimetz M, Parajuli N, Pichl A, et al. Inducible NOS inhibition reverses tobacco-smoke-induced emphysema and pulmonary hypertension in mice. Cell 2011; 147: 293-305.

Hadzic S, Wu CY, Avdeev S, et al. Lung epithelium damage in COPD - an unstoppable pathological event? Cell Signal 2020; 68: 109540.

Szabo C, Ischiropoulos H, Radi R. Peroxynitrite: biochemistry, pathophysiology and development of therapeutics. Nat Rev Drug Discov 2007; 6: 662-680.

Weissmann N, Lobo B, Pichl A, et al. Stimulation of soluble guanylate cyclase prevents cigarette smoke-induced pulmonary hypertension and emphysema. Am J Respir Crit Care Med 2014; 189: 1359-1373.

Ye Q, Dalavanga Y, Poulakis N, et al. Decreased expression of haem oxygenase-1 by alveolar macrophages in idiopathic pulmonary fibrosis. Eur Respir J 2008; 31: 1030-1036.

Odajima N, Betsuyaku T, Nagai K, et al. The role of catalase in pulmonary fibrosis. Respir Res 2010; 11: 183.

Kinnula VL, Hodgson UA, Lakari EK, et al. Extracellular superoxide dismutase has a highly specific localization in idiopathic pulmonary fibrosis/usual interstitial pneumonia. Histopathology 2006; 49: 66-74.

Meyer A, Buhl R, Magnussen $\mathrm{H}$. The effect of oral N-acetylcysteine on lung glutathione levels in idiopathic pulmonary fibrosis. Eur Respir J 1994; 7: 431-436.

Kikuchi N, Ishii Y, Morishima Y, et al. Nrf2 protects against pulmonary fibrosis by regulating the lung oxidant level and Th1/Th2 balance. Respir Res 2010; 11: 31.

Hecker L, Vittal R, Jones T, et al. NADPH oxidase-4 mediates myofibroblast activation and fibrogenic responses to lung injury. Nat Med 2009; 15: 1077-1081.

Amara N, Goven D, Prost F, et al. NOX4/NADPH oxidase expression is increased in pulmonary fibroblasts from patients with idiopathic pulmonary fibrosis and mediates TGFbetal-induced fibroblast differentiation into myofibroblasts. Thorax 2010; 65: 733-738.

Artaud-Macari E, Goven D, Brayer S, et al. Nuclear factor erythroid 2-related factor 2 nuclear translocation induces myofibroblastic dedifferentiation in idiopathic pulmonary fibrosis. Antioxid Redox Signal 2013; 18: 66-79.

Markart P, Luboeinski T, Korfei M, et al. Alveolar oxidative stress is associated with elevated levels of nonenzymatic low-molecular-weight antioxidants in patients with different forms of chronic fibrosing interstitial lung diseases. Antioxid Redox Signal 2009; 11: 227-240.

Pickering AM, Linder RA, Zhang H, et al. Nrf2-dependent induction of proteasome and Pa28alphabeta regulator are required for adaptation to oxidative stress. J Biol Chem 2012; 287: 10021-10031.

Korfei M, von der Beck D, Henneke I, et al. Comparative proteome analysis of lung tissue from patients with idiopathic pulmonary fibrosis (IPF), non-specific interstitial pneumonia (NSIP) and organ donors. J Proteomics 2013; 85: 109-128.

Cantin AM, North SL, Fells GA, et al. Oxidant-mediated epithelial cell injury in idiopathic pulmonary fibrosis. J Clin Invest 1987; 79: 1665-1673.

Waghray M, Cui Z, Horowitz JC, et al. Hydrogen peroxide is a diffusible paracrine signal for the induction of epithelial cell death by activated myofibroblasts. FASEB J 2005; 19: 854-856. 
Koli K, Myllarniemi M, Keski-Oja J, et al. Transforming growth factor-beta activation in the lung: focus on fibrosis and reactive oxygen species. Antioxid Redox Signal 2008; 10: 333-342.

100 Liu RM, Desai LP. Reciprocal regulation of TGF-beta and reactive oxygen species: a perverse cycle for fibrosis. Redox Biol 2015; 6: 565-577.

101 Kuzmenko AI, Wu H, Bridges JP, et al. Surfactant lipid peroxidation damages surfactant protein A and inhibits interactions with phospholipid vesicles. J Lipid Res 2004; 45: 1061-1068.

102 Montuschi P, Ciabattoni G, Paredi P, et al. 8-Isoprostane as a biomarker of oxidative stress in interstitial lung diseases. Am J Respir Crit Care Med 1998; 158: 1524-1527.

103 Rahman I, Skwarska E, Henry M, et al. Systemic and pulmonary oxidative stress in idiopathic pulmonary fibrosis. Free Radic Biol Med 1999; 27: 60-68.

104 Lenz AG, Costabel U, Maier KL. Oxidized BAL fluid proteins in patients with interstitial lung diseases. Eur Respir J 1996; 9: 307-312.

105 Daniil ZD, Papageorgiou E, Koutsokera A, et al. Serum levels of oxidative stress as a marker of disease severity in idiopathic pulmonary fibrosis. Pulm Pharmacol Ther 2008; 21: 26-31.

106 Kuwano K, Nakashima N, Inoshima I, et al. Oxidative stress in lung epithelial cells from patients with idiopathic interstitial pneumonias. Eur Respir J 2003; 21: 232-240.

107 Mora AL, Bueno M, Rojas M. Mitochondria in the spotlight of aging and idiopathic pulmonary fibrosis. J Clin Invest 2017; 127: 405-414.

108 Cheresh P, Kim SJ, Tulasiram S, et al. Oxidative stress and pulmonary fibrosis. Biochim Biophys Acta 2013; 1832: 1028-1040.

109 Yoon YS, Lee JH, Hwang SC, et al. TGF betal induces prolonged mitochondrial ROS generation through decreased complex IV activity with senescent arrest in Mv1Lu cells. Oncogene 2005; 24: 1895-1903.

110 Cucoranu I, Clempus R, Dikalova A, et al. NAD $(\mathrm{P}) \mathrm{H}$ oxidase 4 mediates transforming growth factor-beta1-induced differentiation of cardiac fibroblasts into myofibroblasts. Circ Res 2005; 97: 900-907.

111 Carnesecchi S, Deffert C, Donati Y, et al. A key role for NOX4 in epithelial cell death during development of lung fibrosis. Antioxid Redox Signal 2011; 15: 607-619.

112 Anathy V, Lahue KG, Chapman DG, et al. Reducing protein oxidation reverses lung fibrosis. Nat Med 2018; 24: $1128-1135$.

113 Anathy V, Roberson EC, Guala AS, et al. Redox-based regulation of apoptosis: S-glutathionylation as a regulatory mechanism to control cell death. Antioxid Redox Signal 2012; 16: 496-505.

114 Jones DP. Extracellular redox state: refining the definition of oxidative stress in aging. Rejuvenation Res 2006; 9: $169-181$.

115 Coluzzi E, Colamartino M, Cozzi R, et al. Oxidative stress induces persistent telomeric DNA damage responsible for nuclear morphology change in mammalian cells. PLoS One 2014; 9: e110963.

116 Wang Z, Rhee DB, Lu J, et al. Characterization of oxidative guanine damage and repair in mammalian telomeres. PLoS Genet 2010; 6: e1000951.

117 Snetselaar R, van Batenburg AA, van Oosterhout MFM, et al. Short telomere length in IPF lung associates with fibrotic lesions and predicts survival. PLoS One 2017; 12: e0189467.

118 Alder JK, Chen JJ, Lancaster L, et al. Short telomeres are a risk factor for idiopathic pulmonary fibrosis. Proc Natl Acad Sci USA 2008; 105: 13051-13056.

119 Cronkhite JT, Xing C, Raghu G, et al. Telomere shortening in familial and sporadic pulmonary fibrosis. Am J Respir Crit Care Med 2008; 178: 729-737.

120 Tsakiri KD, Cronkhite JT, Kuan PJ, et al. Adult-onset pulmonary fibrosis caused by mutations in telomerase. Procl Natl Acad Sci USA 2007; 104: 7552-7557.

121 Sala AJ, Bott LC, Morimoto RI. Shaping proteostasis at the cellular, tissue, and organismal level. J Cell Biol 2017; 216: 1231-1241.

122 Lopez-Otin C, Blasco MA, Partridge L, et al. The hallmarks of aging. Cell 2013; 153: 1194-1217.

123 Sen P, Shah PP, Nativio R, et al. Epigenetic mechanisms of longevity and aging. Cell 2016; 166: 822-839.

124 Rubinsztein DC, Marino G, Kroemer G. Autophagy and aging. Cell 2011; 146: 682-695.

125 Keller JN, Hanni KB, Markesbery WR. Possible involvement of proteasome inhibition in aging: implications for oxidative stress. Mech Ageing Dev 2000; 113: 61-70.

126 Murshid A, Eguchi T, Calderwood SK. Stress proteins in aging and life span. Int J Hyperthermia 2013; 29: 442-447.

127 Heydari AR, Takahashi R, Gutsmann A, et al. Hsp70 and aging. Experientia 1994; 50: 1092-1098.

128 Colotti C, Cavallini G, Vitale RL, et al. Effects of aging and anti-aging caloric restrictions on carbonyl and heat shock protein levels and expression. Biogerontology 2005; 6: 397-406.

129 Gutsmann-Conrad A, Heydari AR, You S, et al. The expression of heat shock protein 70 decreases with cellular senescence in vitro and in cells derived from young and old human subjects. Exp Cell Res 1998; 241: 404-413.

130 Erickson RR, Dunning LM, Holtzman JL. The effect of aging on the chaperone concentrations in the hepatic endoplasmic reticulum of male rats: the possible role of protein misfolding due to the loss of chaperones in the decline in physiological function seen with age. J Gerontol A Biol Sci Med Sci 2006; 61: 435-443.

131 Choi BH, Kim JS. Age-related decline in expression of calnexin. Exp Mol Med 2004; 36: 499-503.

132 Naidoo N, Ferber M, Master M, et al. Aging impairs the unfolded protein response to sleep deprivation and leads to proapoptotic signaling. J Neurosci 2008; 28: 6539-6548.

133 Borok Z, Horie M, Flodby P, et al. Grp78 Loss in epithelial progenitors reveals an age-linked role for endoplasmic reticulum stress in pulmonary fibrosis. Am J Respir Crit Care Med 2020; 201: 198-211.

134 Rabek JP, Boylston WH 3rd, Papaconstantinou J. Carbonylation of ER chaperone proteins in aged mouse liver. Biochem Biophys Res Commun 2003; 305: 566-572.

135 Nuss JE, Choksi KB, DeFord JH, et al. Decreased enzyme activities of chaperones PDI and BiP in aged mouse livers. Biochem Biophys Res Commun 2008; 365: 355-361.

136 Ghosh AK, Garg SK, Mau T, et al. Elevated endoplasmic reticulum stress response contributes to adipose tissue inflammation in aging. J Gerontol A Biol Sci Med Sci 2015; 70: 1320-1329.

137 Russ DW, Wills AM, Boyd IM, et al. Weakness, SR function and stress in gastrocnemius muscles of aged male rats. Exp Gerontol 2014; 50: 40-44. 

aging-related genes. Physiol Genomics 2007; 31: 429-440.

139 Wang S, Kaufman RJ. The impact of the unfolded protein response on human disease. J Cell Biol 2012; 197: 857-867.

140 Muller C, Bandemer J, Vindis C, et al. Protein disulfide isomerase modification and inhibition contribute to ER stress and apoptosis induced by oxidized low density lipoproteins. Antioxid Redox Signal 2013; 18: $731-742$.

141 Carbone DL, Doorn JA, Kiebler Z, et al. Modification of heat shock protein 90 by 4-hydroxynonenal in a rat model of chronic alcoholic liver disease. J Pharmacol Exp Ther 2005; 315: 8-15.

142 Cullinan SB, Diehl JA. Coordination of ER and oxidative stress signaling: the PERK/Nrf2 signaling pathway. Int $J$ Biochem Cell Biol 2006; 38: 317-332.

143 Puthalakath H, O’Reilly LA, Gunn P, et al. ER stress triggers apoptosis by activating BH3-only protein Bim. Cell 2007; 129: 1337-1349.

144 Ohoka N, Yoshii S, Hattori T, et al. TRB3, a novel ER stress-inducible gene, is induced via ATF4-CHOP pathway and is involved in cell death. EMBO J 2005; 24: 1243-1255.

145 Namba T, Tanaka K, Ito Y, et al. Positive role of CCAAT/enhancer-binding protein homologous protein, a transcription factor involved in the endoplasmic reticulum stress response in the development of colitis. Am J Pathol 2009; 174: 1786-1798.

146 Yamaguchi H, Wang HG. CHOP is involved in endoplasmic reticulum stress-induced apoptosis by enhancing DR5 expression in human carcinoma cells. J Biol Chem 2004; 279: 45495-45502.

147 McCullough KD, Martindale JL, Klotz LO, et al. Gadd153 sensitizes cells to endoplasmic reticulum stress by down-regulating Bcl2 and perturbing the cellular redox state. Mol Cell Biol 2001; 21: 1249-1259.

148 Marciniak SJ, Yun CY, Oyadomari S, et al. CHOP induces death by promoting protein synthesis and oxidation in the stressed endoplasmic reticulum. Genes Dev 2004; 18: 3066-3077.

149 Mungrue IN, Pagnon J, Kohannim O, et al. CHAC1/MGC4504 is a novel proapoptotic component of the unfolded protein response, downstream of the ATF4-ATF3-CHOP cascade. J Immunol 2009; 182: 466-476.

150 Suyama K, Ohmuraya M, Hirota M, et al. C/EBP homologous protein is crucial for the acceleration of experimental pancreatitis. Biochem Biophys Res Commun 2008; 367: 176-182.

151 Hattori T, Ohoka N, Hayashi H, et al. C/EBP homologous protein (CHOP) up-regulates IL-6 transcription by trapping negative regulating NF-IL6 isoform. FEBS Lett 2003; 541: 33-39.

152 Lerner AG, Upton JP, Praveen PV, et al. IRE1alpha induces thioredoxin-interacting protein to activate the NLRP3 inflammasome and promote programmed cell death under irremediable ER stress. Cell Metab 2012; 16: $250-264$.

153 Hussain SG, Ramaiah KV. Reduced eIF2alpha phosphorylation and increased proapoptotic proteins in aging. Biochem Biophys Res Commun 2007; 355: 365-370.

154 Paz Gavilan M, Vela J, Castano A, et al. Cellular environment facilitates protein accumulation in aged rat hippocampus. Neurobiol Aging 2006; 27: 973-982.

155 Ikeyama S, Wang XT, Li J, et al. Expression of the pro-apoptotic gene gadd153/chop is elevated in liver with aging and sensitizes cells to oxidant injury. J Biol Chem 2003; 278: 16726-16731.

156 Farout L, Friguet B. Proteasome function in aging and oxidative stress: implications in protein maintenance failure. Antioxid Redox Signal 2006; 8: 205-216.

157 Lefaki M, Papaevgeniou N, Chondrogianni N. Redox regulation of proteasome function. Redox Biol 2017; 13: $452-458$.

158 Queisser MA, Yao D, Geisler S, et al. Hyperglycemia impairs proteasome function by methylglyoxal. Diabetes 2010; 59: 670-678.

159 Kumar Deshmukh F, Yaffe D, Olshina MA, et al. The Contribution of the 20S Proteasome to Proteostasis. Biomolecules 2019; 9: 190.

160 Meiners S. Protein Quality Control Coming of Age. In: Rojas M, Meiners S, Le Saux CJ, eds. Molecular Aspects of Aging: Understanding Lung Aging. Hoboken, Wiley, 2014; pp. 27-40.

161 Kapetanou M, Chondrogianni N, Petrakis S, et al. Proteasome activation enhances stemness and lifespan of human mesenchymal stem cells. Free Radic Biol Med 2017; 103: 226-235.

162 Vilchez D, Morantte I, Liu Z, et al. RPN-6 determines C. elegans longevity under proteotoxic stress conditions. Nature 2012; 489: 263-268.

163 Sitte N, Merker K, von Zglinicki T, et al. Protein oxidation and degradation during proliferative senescence of human MRC-5 fibroblasts. Free Radic Biol Med 2000; 28: 701-708.

164 Dasuri K, Zhang L, Keller JN. Oxidative stress, neurodegeneration, and the balance of protein degradation and protein synthesis. Free Radic Biol Med 2013; 62: 170-185.

165 Caniard A, Ballweg K, Lukas C, et al. Proteasome function is not impaired in healthy aging of the lung. Aging (Albany NY) 2015; 7: 776-792.

166 Keller IE, Vosyka O, Takenaka S, et al. Regulation of immunoproteasome function in the lung. Sci Rep 2015; 5: 10230.

167 Kammerl IE, Meiners S. Proteasome function shapes innate and adaptive immune responses. Am J Physiol Lung Cell Mol Physiol 2016; 311: L328-L336.

168 Johnston-Carey HK, Pomatto LC, Davies KJ. The immunoproteasome in oxidative stress, aging, and disease. Crit Rev Biochem Mol Biol 2015; 51: 268-281.

169 Nathan JA, Spinnenhirn V, Schmidtke G, et al. Immuno- and constitutive proteasomes do not differ in their abilities to degrade ubiquitinated proteins. Cell 2013; 152: 1184-1194.

170 Seifert U, Bialy LP, Ebstein F, et al. Immunoproteasomes preserve protein homeostasis upon interferon-induced oxidative stress. Cell 2010; 142: 613-624.

171 Ebstein F, Voigt A, Lange N, et al. Immunoproteasomes are important for proteostasis in immune responses. Cell 2013; 152: 935-937.

172 Angelidis I, Simon LM, Fernandez IE, et al. An atlas of the aging lung mapped by single cell transcriptomics and deep tissue proteomics. Nat Commun 2019; 10: 963.

173 Rajawat YS, Hilioti Z, Bossis I. Aging: central role for autophagy and the lysosomal degradative system. Ageing Res Rev 2009; 8: 199-213. 
174 Lipinski MM, Zheng B, Lu T, et al. Genome-wide analysis reveals mechanisms modulating autophagy in normal brain aging and in Alzheimer's disease. Proc Natl Acad Sci USA 2010; 107: 14164-14169.

175 Khalil H, Tazi M, Caution K, et al. Aging is associated with hypermethylation of autophagy genes in macrophages. Epigenetics 2016; 11: 381-388.

176 Tanase M, Urbanska AM, Zolla V, et al. Role of carbonyl modifications on aging-associated protein aggregation. Sci Rep 2016; 6: 19311.

177 Bueno M, Lai YC, Romero Y, et al. PINK1 deficiency impairs mitochondrial homeostasis and promotes lung fibrosis. J Clin Invest 2015; 125: 521-538.

178 Kelsen SG, Duan X, Ji R, et al. Cigarette smoke induces an unfolded protein response in the human lung: a proteomic approach. Am J Respir Cell Mol Biol 2008; 38: 541-550.

179 Aksoy MO, Kim V, Cornwell WD, et al. Secretion of the endoplasmic reticulum stress protein, GRP78, into the BALF is increased in cigarette smokers. Respir Res 2017; 18: 78.

180 Cappello F, Caramori G, Campanella C, et al. Convergent sets of data from in vivo and in vitro methods point to an active role of Hsp60 in chronic obstructive pulmonary disease pathogenesis. PLoS One 2011; 6: e28200.

181 Dong J, Guo L, Liao Z, et al. Increased expression of heat shock protein 70 in chronic obstructive pulmonary disease. Int Immunopharmacol 2013; 17: 885-893.

182 Hacker S, Lambers C, Hoetzenecker K, et al. Elevated HSP27, HSP70 and HSP90 alpha in chronic obstructive pulmonary disease: markers for immune activation and tissue destruction. Clin Lab 2009; 55: 31-40.

183 Carbone DL, Doorn JA, Kiebler Z, et al. Inhibition of Hsp72-mediated protein refolding by 4-hydroxy-2-nonenal. Chem Res Toxicol 2004; 17: 1459-1467.

184 Min T, Bodas M, Mazur S, et al. Critical role of proteostasis-imbalance in pathogenesis of COPD and severe emphysema. J Mol Med 2011; 89: 577-593.

185 Weidner J, Jarenback L, Aberg I, et al. Endoplasmic reticulum, Golgi, and lysosomes are disorganized in lung fibroblasts from chronic obstructive pulmonary disease patients. Physiol Rep 2018; 6: e13584.

186 Tagawa Y, Hiramatsu N, Kato H, et al. Induction of CCAAT/enhancer-binding protein-homologous protein by cigarette smoke through the superoxide anion-triggered PERK-eIF2alpha pathway. Toxicology 2011; 287: $105-112$.

187 Wang Y, Wu ZZ, Wang W. Inhibition of endoplasmic reticulum stress alleviates cigarette smoke-induced airway inflammation and emphysema. Oncotarget 2017; 8: 77685-77695.

188 Jorgensen E, Stinson A, Shan L, et al. Cigarette smoke induces endoplasmic reticulum stress and the unfolded protein response in normal and malignant human lung cells. BMC Cancer 2008; 8: 229.

189 Geraghty P, Wallace A, D'Armiento JM. Induction of the unfolded protein response by cigarette smoke is primarily an activating transcription factor 4-C/EBP homologous protein mediated process. Int J Chron Obstruct Pulmon Dis 2011; 6: 309-319.

190 Zarcone MC, van Schadewijk A, Duistermaat E, et al. Diesel exhaust alters the response of cultured primary bronchial epithelial cells from patients with chronic obstructive pulmonary disease (COPD) to non-typeable Haemophilus influenzae. Respir Res 2017; 18: 27.

191 van Rijt SH, Keller IE, John G, et al. Acute cigarette smoke exposure impairs proteasome function in the lung. Am J Physiol Lung Cell Mol Physiol 2012; 303: L814-L823.

192 Somborac-Bacura A, van der Toorn M, Franciosi L, et al. Cigarette smoke induces endoplasmic reticulum stress response and proteasomal dysfunction in human alveolar epithelial cells. Exp Physiol 2013; 98: 316-325.

193 Kammerl IE, Dann A, Mossina A, et al. Impairment of immunoproteasome function by cigarette smoke and in chronic obstructive pulmonary disease. Am J Respir Crit Care Med 2016; 193: 1230-1241.

194 Yamada Y, Tomaru U, Ishizu A, et al. Decreased proteasomal function accelerates cigarette smoke-induced pulmonary emphysema in mice. Lab Invest 2015; 95: 625-634.

195 Chen ZH, Kim HP, Sciurba FC, et al. Egr-1 regulates autophagy in cigarette smoke-induced chronic obstructive pulmonary disease. PLoS One 2008; 3: e3316.

196 Lam HC, Cloonan SM, Bhashyam AR, et al. Histone deacetylase 6-mediated selective autophagy regulates COPD-associated cilia dysfunction. J Clin Invest 2013; 123: 5212-5230.

197 Chen ZH, Lam HC, Jin Y, et al. Autophagy protein microtubule-associated protein 1 light chain-3B (LC3B) activates extrinsic apoptosis during cigarette smoke-induced emphysema. Proc Natl Acad Sci USA 2010; 107: $18880-18885$

198 Kim HP, Wang X, Chen ZH, et al. Autophagic proteins regulate cigarette smoke-induced apoptosis: protective role of heme oxygenase-1. Autophagy 2008; 4: 887-895.

199 Mizumura K, Cloonan SM, Nakahira K, et al. Mitophagy-dependent necroptosis contributes to the pathogenesis of COPD. J Clin Invest 2014; 124: 3987-4003.

200 Hoffmann RF, Zarrintan S, Brandenburg SM, et al. Prolonged cigarette smoke exposure alters mitochondrial structure and function in airway epithelial cells. Respir Res 2013; 14: 97.

201 Fujii S, Hara H, Araya J, et al. Insufficient autophagy promotes bronchial epithelial cell senescence in chronic obstructive pulmonary disease. Oncoimmunology 2012; 1: 630-641.

202 Sibinska Z, Tian X, Korfei M, et al. Amplified canonical transforming growth factor-beta signalling via heat shock protein 90 in pulmonary fibrosis. Eur Respir J 2017; 49: 1501941.

203 Chilosi M, Zamo A, Doglioni C, et al. Migratory marker expression in fibroblast foci of idiopathic pulmonary fibrosis. Respir Res 2006; 7: 95.

204 Korfei M, Schmitt S, Ruppert C, et al. Comparative proteomic analysis of lung tissue from patients with idiopathic pulmonary fibrosis (IPF) and lung transplant donor lungs. J Proteome Res 2011; 10: 2185-2205.

205 Lawson WE, Crossno PF, Polosukhin VV, et al. Endoplasmic reticulum stress in alveolar epithelial cells is prominent in IPF: association with altered surfactant protein processing and herpesvirus infection. Am J Physiol Lung Cell Mol Physiol 2008; 294: L1119-L1126.

206 Sellares J, Veraldi KL, Thiel KJ, et al. Intracellular heat shock protein 70 deficiency in pulmonary fibrosis. Am J Respir Cell Mol Biol 2019; 60: 629-636.

207 Tanaka K, Tanaka Y, Namba T, et al. Heat shock protein 70 protects against bleomycin-induced pulmonary fibrosis in mice. Biochem Pharmacol 2010; 80: 920-931. 
Korfei M, Ruppert C, Mahavadi P, et al. Epithelial endoplasmic reticulum stress and apoptosis in sporadic idiopathic pulmonary fibrosis. Am J Respir Crit Care Med 2008; 178: 838-846.

Baek HA, Kim DS, Park HS, et al. Involvement of endoplasmic reticulum stress in myofibroblastic differentiation of lung fibroblasts. Am J Respir Cell Mol Biol 2012; 46: 731-739.

Cha SI, Ryerson CJ, Lee JS, et al. Cleaved cytokeratin-18 is a mechanistically informative biomarker in idiopathic pulmonary fibrosis. Respir Res 2012; 13: 105.

Burman A, Kropski JA, Calvi CL, et al. Localized hypoxia links ER stress to lung fibrosis through induction of C/ EBP homologous protein. JCI Insight 2018; 3: e99543.

Klymenko O, Huehn M, Wilhelm J, et al. Regulation and role of the ER stress transcription factor CHOP in alveolar epithelial type-II cells. J Mol Med 2019; 97: 973-990.

Mulugeta S, Maguire JA, Newitt JL, et al. Misfolded BRICHOS SP-C mutant proteins induce apoptosis via caspase-4- and cytochrome c-related mechanisms. Am J Physiol Lung Cell Mol Physiol 2007; 293: L720-L729.

Mulugeta S, Nguyen V, Russo SJ, et al. A surfactant protein C precursor protein BRICHOS domain mutation causes endoplasmic reticulum stress, proteasome dysfunction, and caspase 3 activation. Am J Respir Cell Mol Biol 2005; 32: 521-530.

Maitra M, Wang Y, Gerard RD, et al. Surfactant protein A2 mutations associated with pulmonary fibrosis lead to protein instability and endoplasmic reticulum stress. J Biol Chem 2010; 285: 22103-22113.

Korfei M, Ruppert C, Loeh B, et al. The role of endoplasmic reticulum (ER) stress in pulmonary fibrosis. Endoplasm Reticul Stress Dis 2016; 3: 16-49.

Lehmann M, Korfei M, Mutze K, et al. Senolytic drugs target alveolar epithelial cell function and attenuate experimental lung fibrosis ex vivo. Eur Respir J 2017; 50: 1602367.

Torres-Gonzalez E, Bueno M, Tanaka A, et al. Role of endoplasmic reticulum stress in age-related susceptibility to lung fibrosis. Am J Respir Cell Mol Biol 2012; 46: 748-756.

Malhotra JD, Miao $\mathrm{H}$, Zhang $\mathrm{K}$, et al. Antioxidants reduce endoplasmic reticulum stress and improve protein secretion. Proc Natl Acad Sci USA 2008; 105: 18525-18530.

Hagiwara SI, Ishii Y, Kitamura S. Aerosolized administration of $\mathrm{N}$-acetylcysteine attenuates lung fibrosis induced by bleomycin in mice. Am J Respir Crit Care Med 2000; 162: 225-331. 53: 705-713.

Theod LA, Gregory SL. The impact of aneuploidy on cellular homeostasis. Free Radic Res 2019; Ghavami S, Yeganeh B, Zeki AA, et al. Autophagy and the unfolded protein response promote profibrotic effects of TGF-beta ${ }_{1}$ in human lung fibroblasts. Am J Physiol Lung Cell Mol Physiol 2018; 314: L493-L504.

Zimmerman KA, Graham LV, Pallero MA, et al. Calreticulin regulates transforming growth factor-beta-stimulated extracellular matrix production. J Biol Chem 2013; 288: 14584-14598.

Kypreou KP, Kavvadas P, Karamessinis P, et al. Altered expression of calreticulin during the development of fibrosis. Proteomics 2008; 8: 2407-2419.

Van Duyn Graham L, Sweetwyne MT, Pallero MA, et al. Intracellular calreticulin regulates multiple steps in fibrillar collagen expression, trafficking, and processing into the extracellular matrix. J Biol Chem 2010; 285: 7067-7078.

Harding HP, Zhang Y, Bertolotti A, et al. Perk is essential for translational regulation and cell survival during the unfolded protein response. Mol Cell 2000; 5: 897-904.

Bhardwaj M, Leli NM, Koumenis C, et al. Regulation of autophagy by canonical and non-canonical ER stress responses. Semin Cancer Biol 2019; in press [https://doi.org/10.1016/j.semcancer.2019.11.007].

Margariti A, Li H, Chen T, et al. XBP1 mRNA splicing triggers an autophagic response in endothelial cells through BECLIN-1 transcriptional activation. J Biol Chem 2013; 288: 859-872.

Baker TA, Bach HH 4th, Gamelli RL, et al. Proteasomes in lungs from organ donors and patients with end-stage pulmonary diseases. Physiol Res 2014; 63: 311-319.

Semren N, Welk V, Korfei M, et al. Regulation of $26 \mathrm{~S}$ proteasome activity in pulmonary fibrosis. Am J Respir Crit Care Med 2015; 192: 1089-1101.

Wang WJ, Mulugeta S, Russo SJ, et al. Deletion of exon 4 from human surfactant protein C results in aggresome formation and generation of a dominant negative. J Cell Sci 2003; 116: 683-692.

Gustafsson M, Thyberg J, Naslund J, et al. Amyloid fibril formation by pulmonary surfactant protein C. FEBS Lett 1999; 464: 138-142. 2511-2518.

Song C, Xiao Z, Nagashima $\mathrm{K}$, et al. The heavy metal cadmium induces valosin-containing protein (VCP)-mediated aggresome formation. Toxicol Appl Pharmacol 2008; 228: 351-363.

Kimura Y, Kakizuka A. Polyglutamine diseases and molecular chaperones. IUBMB Life 2003; 55: 337-345.

Patel AS, Lin L, Geyer A, et al. Autophagy in idiopathic pulmonary fibrosis. PLoS One 2012; 7: e41394.

Araya J, Kojima J, Takasaka N, et al. Insufficient autophagy in idiopathic pulmonary fibrosis. Am J Physiol Lung Cell Mol Physiol 2013; 304: L56-L69.

Kim YC, Guan KL. mTOR: a pharmacologic target for autophagy regulation. J Clin Invest 2015; 125: 25-32.

Gui YS, Wang L, Tian X, et al. mTOR Overactivation and compromised autophagy in the pathogenesis of pulmonary fibrosis. PLoS One 2015; 10: e0138625.

Gupta SS, Zeglinski MR, Rattan SG, et al. Inhibition of autophagy inhibits the conversion of cardiac fibroblasts to cardiac myofibroblasts. Oncotarget 2016; 7: 78516-78531. primary human atrial myofibroblasts. Cell Death Dis 2015; 6: e1696.

Hernandez-Segura A, Nehme J, Demaria M. Hallmarks of cellular senescence. Trends Cell Biol 2018; 28: 436-453.

Xiong Y, Zhou L. The signaling of cellular senescence in diabetic nephropathy. Oxid Med Cell Longev 2019; 2019: 7495629.

Salama R, Sadaie M, Hoare M, et al. Cellular senescence and its effector programs. Genes Dev 2014; 28: 99-114. Rayess H, Wang MB, Srivatsan ES. Cellular senescence and tumor suppressor gene p16. Int J Cancer 2012; 130: $1715-1725$. 
Serrano M, Lin AW, McCurrach ME, et al. Oncogenic ras provokes premature cell senescence associated with accumulation of p53 and p16INK4a. Cell 1997; 88: 593-602.

Rodier F, Campisi J. Four faces of cellular senescence. J Cell Biol 2011; 192: 547-556.

Tsuji T, Aoshiba K, Nagai A. Alveolar cell senescence in patients with pulmonary emphysema. Am J Respir Crit Care Med 2006; 174: 886-893.

Amsellem V, Gary-Bobo G, Marcos E, et al. Telomere dysfunction causes sustained inflammation in chronic obstructive pulmonary disease. Am J Respir Crit Care Med 2011; 184: 1358-1366.

Aoshiba K, Zhou F, Tsuji T, et al. DNA damage as a molecular link in the pathogenesis of COPD in smokers. Eur Respir J 2012; 39: 1368-1376.

Holz O, Zuhlke I, Jaksztat E, et al. Lung fibroblasts from patients with emphysema show a reduced proliferation rate in culture. Eur Respir J 2004; 24: 575-579.

Muller KC, Welker L, Paasch K, et al. Lung fibroblasts from patients with emphysema show markers of senescence in vitro. Respir Res 2006; 7: 32.

Kumar M, Seeger W, Voswinckel R. Senescence-associated secretory phenotype and its possible role in chronic obstructive pulmonary disease. Am J Respir Cell Mol Biol 2014; 51: 323-333.

Horowitz JC, Martinez FJ, Thannickal VJ. Mesenchymal cell fate and phenotypes in the pathogenesis of emphysema. COPD 2009; 6: 201-210.

Togo S, Holz O, Liu X, et al. Lung fibroblast repair functions in patients with chronic obstructive pulmonary disease are altered by multiple mechanisms. Am J Respir Crit Care Med 2008; 178: 248-260.

Zhang J, Wu L, Qu JM, et al. Pro-inflammatory phenotype of COPD fibroblasts not compatible with repair in COPD lung. J Cell Mol Med 2012; 16: 1522-1532.

Sundar IK, Rashid K, Gerloff J, et al. Genetic ablation of p16 $6^{\mathrm{INK} 4 \mathrm{a}}$ does not protect against cellular senescence in mouse models of chronic obstructive pulmonary disease/emphysema. Am J Respir Cell Mol Biol 2018; 59: 189-199.

Hamsanathan S, Alder JK, Sellares J, et al. Cellular senescence: the Trojan Horse in chronic lung diseases. Am J Respir Cell Mol Biol 2019; 61: 21-30.

Barnes PJ. Senescence in COPD and its comorbidities. Annu Rev Physiol 2017; 79: 517-539.

Baker JR, Donnelly LE, Barnes PJ. Senotherapy: a new horizon for COPD therapy. Chest 2020; in press [https:// doi.org/10.1016/j.chest.2020.01.027].

Barnes PJ, Baker J, Donnelly LE. Cellular senescence as a mechanism and target in chronic lung diseases. Am J Respir Crit Care Med 2019; 200: 556-564.

Zhu Y, Tchkonia T, Pirtskhalava T, et al. The Achilles' heel of senescent cells: from transcriptome to senolytic drugs. Aging Cell 2015; 14: 644-658.

Barnes PJ. Oxidative stress-based therapeutics in COPD. Redox Biol 2020; 33: 101544.

Schafer MJ, White TA, Iijima K, et al. Cellular senescence mediates fibrotic pulmonary disease. Nat Commun 2017; 8: 14532 .

Hohmann MS, Habiel DM, Coelho AL, et al. Quercetin enhances ligand-induced apoptosis in senescent idiopathic pulmonary fibrosis fibroblasts and reduces lung fibrosis in vivo. Am J Respir Cell Mol Biol 2019; 60: 28-40.

Li Y, Liang J, Yang T, et al. Hyaluronan synthase 2 regulates fibroblast senescence in pulmonary fibrosis. Matrix Biol 2016; 55: 35-48.

Cui H, Ge J, Xie N, et al. miR-34a inhibits lung fibrosis by inducing lung fibroblast senescence. Am J Respir Cell Mol Biol 2017; 56: 168-178.

Jun JI, Lau LF. Resolution of organ fibrosis. J Clin Invest 2018; 128: 97-107.

Krizhanovsky V, Yon M, Dickins RA, et al. Senescence of activated stellate cells limits liver fibrosis. Cell 2008; 134: 657-667.

Jun JI, Lau LF. The matricellular protein CCN1 induces fibroblast senescence and restricts fibrosis in cutaneous wound healing. Nat Cell Biol 2010; 12: 676-685.

Alder JK, Barkauskas CE, Limjunyawong N, et al. Telomere dysfunction causes alveolar stem cell failure. Proc Natl Acad Sci USA 2015; 112: 5099-5104.

2 Naikawadi RP, Disayabutr S, Mallavia B, et al. Telomere dysfunction in alveolar epithelial cells causes lung remodeling and fibrosis. JCI Insight 2016; 1: e86704.

Kuwano K, Kunitake R, Kawasaki M, et al. P21Waf1/Cip1/Sdil and p53 expression in association with DNA strand breaks in idiopathic pulmonary fibrosis. Am J Respir Crit Care Med 1996; 154: 477-483.

Disayabutr S, Kim EK, Cha SI, et al. miR-34 miRNAs regulate cellular senescence in type ii alveolar epithelial cells of patients with idiopathic pulmonary fibrosis. PLoS One 2016; 11: e0158367.

Alvarez D, Cardenes N, Sellares J, et al. IPF lung fibroblasts have a senescent phenotype. Am J Physiol Lung Cell Mol Physiol 2017; 313: L1164-L1173.

Schuliga M, Pechkovsky DV, Read J, et al. Mitochondrial dysfunction contributes to the senescent phenotype of IPF lung fibroblasts. J Cell Mol Med 2018; 22: 5847-5861.

Zhang Y, Jones KD, Achtar-Zadeh N, et al. Histopathological and molecular analysis of idiopathic pulmonary fibrosis lungs from patients treated with pirfenidone or nintedanib. Histopathology 2019; 74: 341-349.

Nagaraja MR, Tiwari N, Shetty SK, et al. p53 expression in lung fibroblasts is linked to mitigation of fibrotic lung remodeling. Am J Pathol 2018; 188: 2207-2222.

Korfei M, Skwarna S, Henneke I, et al. Aberrant expression and activity of histone deacetylases in sporadic idiopathic pulmonary fibrosis. Thorax 2015; 70: 1022-1032.

Kramer OH. HDAC2: a critical factor in health and disease. Trends Pharmacol Sci 2009; 30: 647-655.

Yao C, Guan X, Carraro G, et al. Senescence of alveolar stem cells drives progressive pulmonary fibrosis. bioRxiv 2019; preprint [https://doi.org/10.1101/820175].

Justice JN, Nambiar AM, Tchkonia T, et al. Senolytics in idiopathic pulmonary fibrosis: results from a first-in-human, open-label, pilot study. EBioMedicine 2019; 40: 554-563.

van Deursen JM. Senolytic therapies for healthy longevity. Science 2019; 364: 636-637. 